\title{
A Novel Method of Defect Detection Based on Experimental Investigation of Galvanized Steel Welded Plates Using Wobble Laser Process
}

Sasan Sattarpanah Karganroudi ( $\sim$ sasan_sattarpanahkarganroudi@uqar.ca )

Université du Québec à Rimouski https://orcid.org/0000-0001-7226-5671

Ahmad Aminzadeh

Université du Québec à Rimouski

Vincent Blériot Feujofack Kemda

Université du Québec à Rimouski

Noureddine Barka

Université du Québec à Rimouski

\section{Research Article}

Keywords: Laser beam welding (LBW), Galvanized steel, Hardness mapping, Analysis of variance (ANOVA), Response surface method (RSM)

Posted Date: March 22nd, 2021

DOI: https://doi.org/10.21203/rs.3.rs-334951/v1

License: (9) This work is licensed under a Creative Commons Attribution 4.0 International License.

Read Full License 


\title{
A novel method of defect detection based on experimental investigation of galvanized steel welded plates using wobble laser process
}

\author{
Sasan Sattarpanah Karganroudi ${ }^{{ }^{*},}$, Ahmad Aminzadeh ${ }^{1}$, Vincent Blériot Feujofack Kemda ${ }^{1}$, \\ Noureddine Barka ${ }^{1}$ \\ ${ }^{1}$ Department of Mathematics, Computer Science and Engineering, Université du Québec à Rimouski, Rimouski, Québec, Canada \\ *Corresponding author: sasan_sattarpanahkarganroudi@uqar.ca
}

\begin{abstract}
This paper aims at investigating the effect of laser welding parameters on the hardness profile, using hardness mapping analyses, and welding geometry of galvanized steel plates. Hardness distribution and geometry deflection of galvanized welded thin plates are commonly applied in fields where the weld quality is of utmost importance. Due to the welding process and material condition, welding galvanized steel is one of the problematic matters in welding technology. Here, the design of experiment (DOE) approach is used to study the effect of process parameters. Using a pattern matrix of micro-indentation hardness experiment, the welding defects are visualized on hardness profile of the weld cross-section. The effect of process parameters on welding defect formation is then qualitatively analyzed. The geometrical defects of welding such as weld width and voids are then quantitatively studied based on analysis of variance (ANOVA), and predictive models of welding voids and weld seam width are developed based on the regression method. Response surface method (RSM) is then applied to define the trend of process factors interaction on the welding defects. The experimental results confirm the reliability of developed predictive models of welding defects geometry, weld width, and voids area of laser-welded galvanized plates.
\end{abstract}

Keywords: Laser beam welding (LBW); Galvanized steel; Hardness mapping; Analysis of variance (ANOVA); Response surface method (RSM)

\section{Introduction}

In modern industrial applications, a variety of materials types and coating methods have been used to improve and enhance manufacturing performance and production. In the past decade, engineers and scholars observed galvanized steel coils as the most functional material in order to protect products from corrosion and rusting while preserving good enough formability, durability, and strength [1]. This significant flexibility makes it appropriate to a wide range of projects and industries, including agriculture [2], solar [3], automotive [4], [5], construction [6], and telecommunication [7]. Galvanization or galvanizing is a process of coating a cover of zinc to steel or iron to avoid corrosion and rusting. To this end, industrial galvanization of steels such as hot-dip galvanizing [8], pre-galvanizing [9], and Electro galvanizing [10] are developed. Among them, hot-dip galvanizing is a promising technology in the manufacturing process, in which the parts are dipped in a molten hot zinc bath. Since this method is an economical choice that can be rapidly performed on both simple and complex profiles, it is the most common technique among manufacturers and industries. However, a reaction between zinc-oxide and carbon dioxide in final products would be a cause of catastrophic failures during their service life [11]. The material characterization and the zinc coating layer specifications reveal that welding of galvanized sheets is one of the critical processes in welding technology, especially during laser beam welding.

The laser material processing and especially laser welding offers a small heat-affected zone (HAZ) and deep penetration capacity, which provides deep welding and narrow [12]. Recently, the automation of laser operation has been increasing welding performance and cadence. However, applying a high energy concentration in welding galvanized steel forms poor weld quality, including porosities and voids in the weld seam. In this regard, laser-welded galvanized steel plates very often show welding defects that significantly affect the mechanical strength of welding. The leading cause of this problem is the evaporation 
of zinc contained in the protective layers during welding. Based on the literature, the difference between the melting point of $\mathrm{Fe}\left(1538^{\circ} \mathrm{C}\right)$ and $\mathrm{Zn}\left(906^{\circ} \mathrm{C}\right)$ causes critical problems such as the generation of $\mathrm{ZnO}$, which stimulates the formation of spatters during laser welding of galvanized sheets [13]. In this regard, Song et al. [14] designed a new setup (panda beam), which is a mixture of two Bragg gratings in dissimilar guidelines to make a splitting beam. According to their results, using panda beam, solder melting zinc, and coating are performed to improve the welding quality. Recently, the escape of zinc vapor in the weld pool of laser-welded galvanized steels is investigated via numerical and experimental approaches [15]-[17]. Zapf et al. [18] have studied the laser weldability of additive manufacturing (AM) powders, which is the mixture of conventional galvanized steel (HCT780XD) and additive, to reach hybrid structures that fulfill both mechanical and economic requirements. Based on these results, microstructures and the determined mechanical properties indicate good weldability of this material, and hardening is occurred in the weld seam [19]. Luo et al. [20] have performed experimental mechanical and metrological characterization of different thicknesses ASSAPH440 high strength steels welded by $\mathrm{CO}_{2}$ laser welding and reported that the highest microhardness comes about at the center of the welding cross-section. In the same context, Chen et al. [21] developed a vent hole in $\mathrm{CO}_{2}$ laser welding to improve the welding quality and to minimize the porosities generation. Khan et al. [22] performed a comprehensive review on laser welding of coated $22 \mathrm{MnB}_{5}$ presshardened steel. It worth noting that condition monitoring and damage detections are inevitable procedures during modern laser welding. The real-time monitoring of laser beam welding and predicting defects formation during laser welding based on artificial intelligence (AI) methods such as neural network approaches (NNA), as well as advanced manufacturing technologies based on AI are developed [23], [24]. In addition, experimental and numerical analysis concerning the migration behavior of aluminum - steel by twin-spot laser welding-brazing method is conducted [25], [26]. These studies demonstrate the increase of joint strength with maximum migration distance, leading to a maximum joint strength of $133.14 \mathrm{MPa}$. Mohammadpour et al. [27] studied the impact of laser beam inclination angle on galvanized steel laser brazing quality, discovering that negative travel angles help moving zinc evaporation front ahead of the wetting and reduce the interaction between the zinc vapor and melt pool. Also, the formation mechanism of liquid metal embrittlement (LME) in laser lap welding of zinc-coated GEN3, and resistance spot welding (RSW) of dual-phase (DP) steels based on numerical and experimental validation are studied, leading to a promising model of LME crack formation [28], [29].

In this paper, geometrical defects of laser-welded galvanized steel plates during butt-joint configuration using a reinforcing plate are studied. A novel method of 3D hardness profile representation is used to qualitatively analyze the welding quality in the cross-section of weld seam with respect to the welding process parameters. Then, qualitative analyses based on statistical variation analyses (ANOVA) is applied to find the main effective process parameters on welding geometry and the formation of voids in the weld seam. In order to select experimental parameters considered in the study, Ishikawa's diagram is developed as depicted in Figure 1. [30]. To this end, the cause-effect diagram presents generally five categories of process parameters that may affect the welding geometry and hardness profile of galvanized steel welded joints. These categories are material characterization (thickness of welded plates, chemical composition, and thickness of zinc layer), machine stability and limitations (frequency, the amplitude of vibration, and laser source), environment (welding environment, gas shielding, and temperature), methods (welding configuration, laser spot nature and characterization, and plates clamping), and means (laser beam gadget, and protection gas). The process parameters are presented in Table 1. Based on this analysis, four key process parameters, laser power $(\mathrm{P})$, welding speed $(\mathrm{V})$, scanning frequency (f), and gaps between main plates $(\mathrm{g})$, in three levels of variation are selected to study their impact on welding geometry and hardness profile. The hardness distribution of weld seam using 3D hardness mapping along with geometrical dimensioning of welding is qualitatively investigated with respect to welding parameters tuning. Microindentation hardness tests on welding cross-sections are used to develop the 3D hardness profile. An optimized resolution with a hardness pattern matrix on the cross-section of welding may bring out HAZ and 
voids areas. The welding geometry (weld width), as well as porosity and void areas at seam cross-section, are then measured under a microscope. Using statistical analyses, ANOVA, the influence of four key process parameters on welding geometry, and porosity formation are investigated. These analyses lead to developing regression models predicting the welding width and porosity areas in the cross-section of welding. Then, the response surface method (RSM) is applied to present the trend of responses (welding geometry) according to the process parameters to find an optimal combination of parameters that lead to quality welding. The results are promising, which present a good conformation between predictive models and experimental results. In fact, this model would be a desirable investigation to opening real-time monitoring and intelligent manufacturing by HAZ detection and distribution of hardness in welding frameworks like door panels in automobile companies and ship industries.

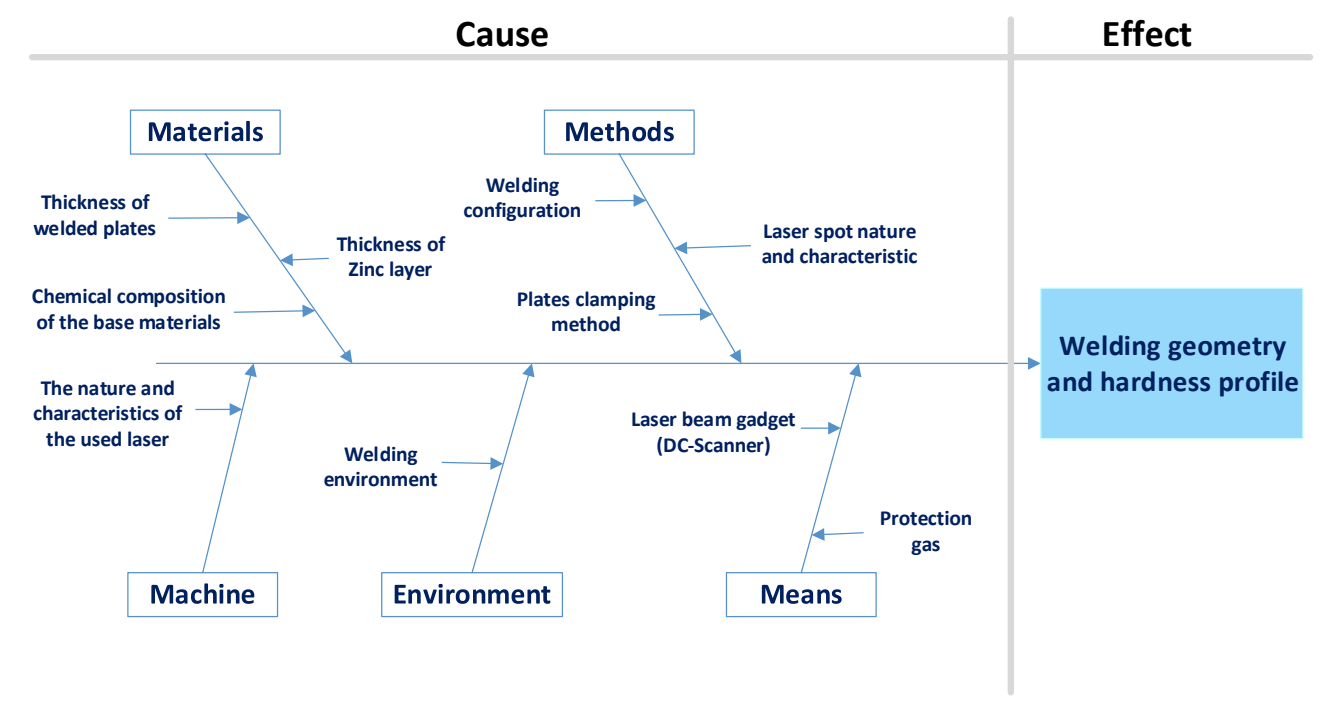

Figure 1. Ishikawa's diagram analyzing the effect of galvanized steel laser welding on welding geometry and harness profile.

Table 1. Galvanized steel laser welding parameters and variation ranges.

\begin{tabular}{|c|c|c|c|c|c|}
\hline Factors & Abbreviation & $\begin{array}{c}\text { Variation } \\
\text { ranges }\end{array}$ & Unit & Detailed information & Type \\
\hline Laser power & $\mathrm{P}$ & $1200-1600$ & $\mathrm{~W}$ & $\begin{array}{l}\text { Control the amount of energy } \\
\text { absorbed into the workpiece. }\end{array}$ & Variable \\
\hline Welding speed & $\mathrm{V}$ & $7-13$ & $\mathrm{~mm} / \mathrm{s}$ & $\begin{array}{l}\text { The velocity of moving beam inline } \\
\text { workpiece. }\end{array}$ & Variable \\
\hline Wobbling frequency & $\mathrm{f}$ & $150-200$ & $\mathrm{~Hz}$ & $\begin{array}{l}\text { Rapidly rotate beam to create weld } \\
\text { shape by increasing the weld width. }\end{array}$ & Variable \\
\hline $\begin{array}{l}\text { Gap between main } \\
\text { plates }\end{array}$ & $\mathrm{g}$ & $0.15-0.55$ & $\mathrm{~mm}$ & $\begin{array}{l}\text { The gap between two butt-welded } \\
\text { plates. }\end{array}$ & Variable \\
\hline focal spot diameter & $d_{f}$ & 0.42 & $\mathrm{~mm}$ & $\begin{array}{l}\text { The smallest diameter at the focal } \\
\text { plane when focused by a lens. }\end{array}$ & Fix \\
\hline Focal length & - & 310 & $\mathrm{~mm}$ & $\begin{array}{l}\text { The distance between the lens and } \\
\text { the workpiece. }\end{array}$ & Fix \\
\hline Wobbling amplitude & - & 1 & $\mathrm{~mm}$ & $\begin{array}{l}\text { The maximum beam oscillation } \\
\text { amplitude on the workpiece. }\end{array}$ & Fix \\
\hline Thickness ratio & - & 2.25 & $\mathrm{~mm}$ & $\begin{array}{l}\text { The ratio between the thickness of } \\
\text { main plates and reinforcement plate. }\end{array}$ & Fix \\
\hline
\end{tabular}




\section{Material and method}

\subsection{Preparation of specimens and experimental set-up}

Considering the laser welding parameters set up, some main parameters such as focal spot diameter, focal length, scanner amplitude, and thickness ratio (the main plates and the reinforcement plate) are set as constant level $0.42 \mathrm{~mm}, 310 \mathrm{~mm}, 1 \mathrm{~mm}$, and $2.25 \mathrm{~mm}$, respectively. Moreover, factors such as plate clamping force, and the thickness of zinc layers are identified as potential noise sources. To carry out the welding, edge surfaces are primarily polished using 600-grit sandpapers and cleaned using surface cleaner (acetone) to remove chemical contaminants. The Fiber laser welding process is then used to join the sheets together using a six-axis-robotic system FANUC M-710ic with a $1.2 \mathrm{~kW}$ Fiber laser source to implement the automatic laser beam welding. The robotic laser-welding configuration is illustrated in Figure 2, and the available range of laser welding machine parameters is listed in Table 2.

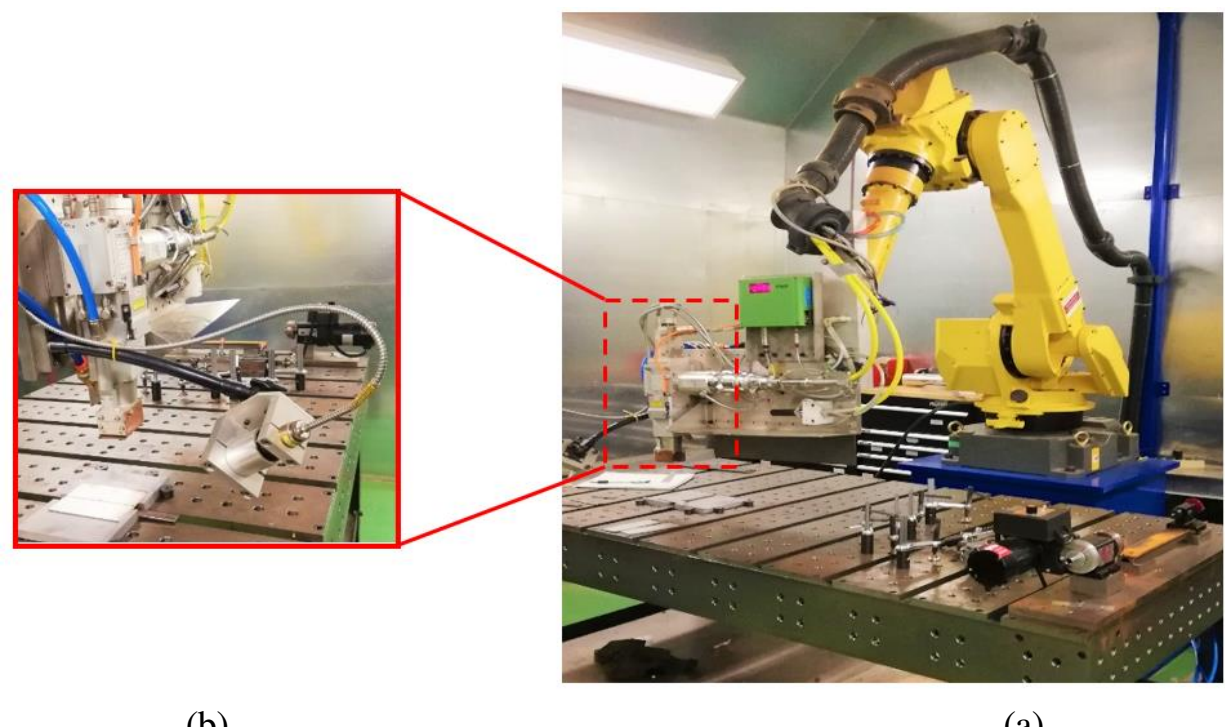

(b)

(a)

Figure 2. Automatic mechanism of welding machine a) six-axis-robotic system FANUC M-710ic and b) Laser welding cell.

Table 2. The accessible range for the laser factors.

\begin{tabular}{lc}
\hline Laser parameters & Available range \\
\hline Welding power & $500-3000 \mathrm{~W}$ \\
Focusing & $310 \mathrm{~mm}$ \\
Fiber diameter & 200 and $500 \mathrm{microns}$ \\
Oscillation & $0-150 \mathrm{~mm}$ \\
Frequency & $0-1000 \mathrm{HZ}$ \\
Focus diameter & $0.45 \mathrm{~mm}$ (Fixed) \\
\hline
\end{tabular}

During the laser process, the high-power single-mode laser beam is adjusted with a beam oscillation (wobbling) wherein the laser spot has oscillated transversally with respect to the welding direction. In order to expand the width of the weld simultaneously keeping the high efficiency of a deep keyhole, wobbling effectively boosts the spot diameter during laser welding [31]. Here, a sinusoidal oscillation trajectory with high and alternating speed is used in this study. As already mentioned, the laser welding such as focal spot 
diameter, focal length, and scanner amplitude are adjusted $0.42 \mathrm{~mm}$ (on the top of the surface), $310 \mathrm{~mm}$, $1 \mathrm{~mm}$, respectively. Regarding hardness measurement in the narrow laser-welded seam, micro-indentation hardness (using Clemex ${ }^{\mathrm{TM}}$ machine) is used to define the hardness distribution based on ASTM E2546 standard [32].

In this study, hot-dipped galvanized steels (ASTM A653) are butt-welded via a Yb-Fiber laser beam welding. To be more specific, a zinc layer at a coating density of $282.6 \mathrm{~g} / \mathrm{cm}^{3}$ is applied on the galvanized steels as a coating film with a galvanized thickness of $0.853 \mathrm{~mm}$ (22 gauge). Furthermore, a reinforcing steel plate (ASTM A36) is used as a support in the backside of galvanized joining plates based on ASTM A36. Generally, ASTM A36 and A653 steels are frequently used in the automotive industry, for which Table 3 and Table 4 present their chemical composition and mechanical properties. The galvanized steel thickness is $1.8 \mathrm{~mm}$, and the thickness of the reinforcing plate is $0.8 \mathrm{~mm}$. Once the optimization of welding hardness and geometry is achieved, it will be possible to optimize its strength in traction.

Table 3. ASTM A653 hot dipped galvanized steel and ASTM A36 steel chemical composition in \% [33], [34].

\begin{tabular}{ccccccccccccc}
\hline $\begin{array}{c}\text { Chemical } \\
\text { compositi } \\
\text { on }\end{array}$ & $\mathbf{C}$ & $\mathbf{M n}$ & $\mathbf{P}$ & $\mathbf{S}$ & $\mathbf{C u}$ & $\mathbf{S i}$ & $\mathbf{N i}$ & $\mathbf{C r}$ & $\mathbf{M o}$ & $\mathbf{C b}$ & $\mathbf{V}$ & $\mathbf{T i}$ \\
\hline $\mathrm{A} 653$ & 0.15 & 0.60 & 0.03 & 0.035 & 0.25 & - & 0.2 & 0.15 & 0.06 & 0.008 & 0.008 & 0.025 \\
$\mathrm{~A} 36$ & 0.27 & 1.03 & 0.04 & 0.05 & 0.20 & 0.280 & $<0.1$ & $<0.08$ & $<0.1$ & - & - & - \\
\hline
\end{tabular}

Table 4. ASTM A653 hot dipped galvanized steel and ASTM A36 steel mechanical properties [31], [32].

\begin{tabular}{ccccc}
\hline Mechanical properties & $\begin{array}{c}\text { Yield strength } \\
{[\mathbf{M P a}]}\end{array}$ & $\begin{array}{c}\text { Ultimate tensile strength } \\
{[\mathbf{M P a}]}\end{array}$ & $\begin{array}{c}\text { Elongation } \\
{[\%]}\end{array}$ & Hardness \\
& 277.5 & 363.8 & 37.5 & 121 \\
\hline A653 & 441.3 & 503.3 & 30 & 120 \\
\hline A36 & $4 \mathbf{H V}]$ \\
\hline
\end{tabular}

\subsection{Design of experiments (DOE)}

The term of design of experiments (DOE) is associated with planning an efficient amount and combination of experiments required to achieve exhaustive experimentation, which is statistically meaningful. DOE is a scientific approach that allows researchers to understand better the aspects of a process and to determine how inputs (factors) affect outputs (responses). In this study, DOEs can be divided into three main phases: planning, carrying out the tests, and analyzing the results. In this section, we focus on the planning of experiments. A complete factorial design of experiment can be used for a comprehensive effect study of process parameters and their interactions on the responses. However, the number of trials required for a complete factorial design can rise to 81 tests, which will be very expensive and time-consuming. Since this is an exploration of a welding configuration, the goal is to validate its feasibility and to highlight its contribution considering hardness and welding geometry. For this purpose, an orthogonal-array-based design of experiments using Taguchi method is applied in this study wherein an L 9 orthogonal matrix corresponding to nine (9) experimental tests is addressed. Using Taguchi planning method each test consists of a unique combination of parameter levels as shown in Table 5. 
Table 5. Design of experiences, $L_{9}$ orthogonal matrix.

\begin{tabular}{ccccc|}
\hline \multirow{2}{*}{ Tests } & \multicolumn{4}{c|}{ Factors } \\
\cline { 2 - 5 } No. & $\mathrm{P}[\mathrm{W}]$ & $\mathrm{V}[\mathrm{mm} / \mathrm{s}]$ & $\mathrm{f}[\mathrm{Hz}]$ & $\mathrm{g}[\mathrm{mm}]$ \\
\cline { 2 - 5 } $\mathbf{1}$ & 1200 & 13 & 150 & 0.55 \\
$\mathbf{2}$ & 1200 & 10 & 175 & 0.35 \\
$\mathbf{3}$ & 1200 & 7 & 200 & 0.15 \\
$\mathbf{4}$ & 1400 & 13 & 175 & 0.15 \\
$\mathbf{5}$ & 1400 & 10 & 200 & 0.55 \\
$\mathbf{6}$ & 1400 & 7 & 150 & 0.35 \\
$\mathbf{7}$ & 1600 & 13 & 200 & 0.35 \\
$\mathbf{8}$ & 1600 & 10 & 150 & 0.15 \\
$\mathbf{9}$ & 1600 & 7 & 175 & 0.55 \\
\hline
\end{tabular}

\subsection{Hardness measurement}

The hardness of a solid material can be defined as a measure of its resistance to a permanent change in shape when subjected to constant compressive stress [32]. Micro-indentation hardness is applied in this study to define the hardness distribution based on ASTM E2546 standard [35]. This method is widely used in industrial applications to characterize the mechanical properties of materials. Hardness is obtained after micro-indentation at loads ranging from 1 to $1000 \mathrm{gf}$ [36], and in this study, a force of $300 \mathrm{gf}$ is used as micro-indentation loading. In this current study, the hardness measurement procedure is performed for each welding cross-section in accordance with a matrix pattern. From a polished cross-section of each welding, indentation points of size $13 \times 51$ are made (200 microns vertical spacing and 200 microns horizontal spacing), which provides a hardness profile over the entire area of the welding cross-section (presented in Figure 3).

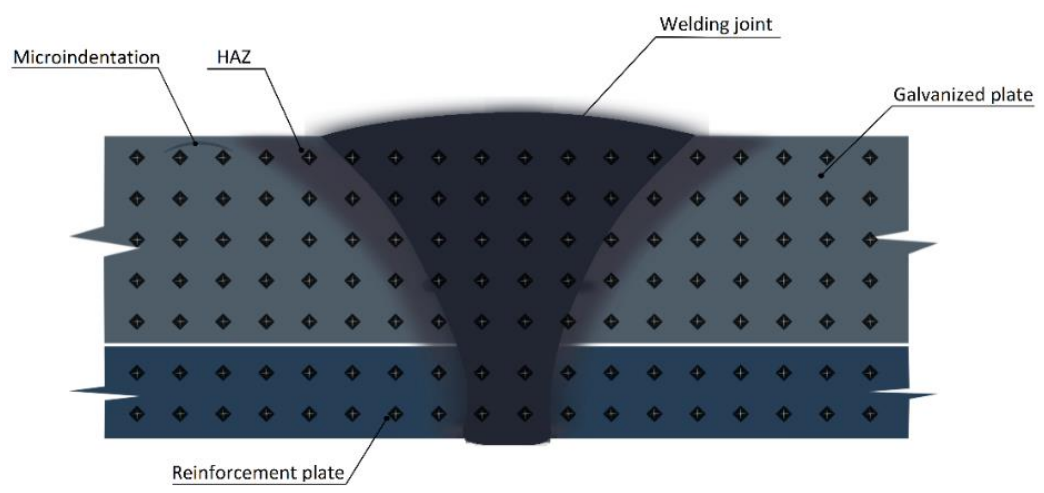

Figure 3. Schematic representation of micro-indentation matrix pattern over a welding cross-section. [37]

\section{Results and discussion}

\subsection{Hardness profile of welding}

The contour plots and 3D hardness profiles of laser-welded galvanized plates with a reinforcement plate are developed in MATLAB ${ }^{\mathrm{TM}}$. These plots are illustrated using nine (9) different combinations of process parameters. Regarding micro-indentation tests, hardness profiles are reconstructed based on Vickers hardness in the weld zone. Generally, the zones with excessive hardness values, over $140 \mathrm{HV}$, indicate Heataffected zones (HAZ) wherein a localized heat treatment is implemented due to laser beam concentration of 
heating energy and high cooling rate (thermal conductivity by dint of steels high heat conduction) which are represented by red, orange, yellow, and green colors in harness profile plots. Furthermore, there are deep blue zones, soft zones with less than $40 \mathrm{HV}$, which represent porosities and voids. According to these contour and surface plots in Figure 4, it could be concluded that the most vulnerable area is located on the top of the weld cross-section ( $<40 \mathrm{HV})$. These areas can be fracture initiation points under cyclic loads, which should be designed with a relatively high safety factor. Generally, once the color changes from deep blue $(40 \mathrm{HV})$ and gradually increases to deep red $(240 \mathrm{HV})$, it could be concluded that the hardness distribution is due to the heat-affected zone during the welding process. Conversely, the abrupt color changes from deep blue to red can be interpreted as abnormal cases that can be interpreted as voids or welding defects.

Here, the effect of welding speed, welding power, scan frequency, and gap on the hardness and geometry are investigated. Figure 4 shows the hardness profiles for test 1 , where the welding speed and scanning frequency are set as $13 \mathrm{~mm} / \mathrm{s}$ and $150 \mathrm{~Hz}$, and the horizontal gap between galvanized plates is $0.55 \mathrm{~mm}$. Regarding test 2 (shown in Figure 5), the welding speed, scanning frequency, and horizontal gap between galvanized plates are set as $10 \mathrm{~mm} / \mathrm{s}, 175 \mathrm{~Hz}$, and $0.35 \mathrm{~mm}$, respectively. In addition, these input parameters are adjusted as $7 \mathrm{~mm} / \mathrm{s}, 200 \mathrm{~Hz}$, and $0.15 \mathrm{~mm}$ in test 3 (Figure 6). Considering the constant welding power of $1200 \mathrm{~W}$, a horizontal deep blue region between $1500 \mu \mathrm{m}$ and $2000 \mu \mathrm{m}$ weld depth in the lower section of welding can be detected. This issue is generated due to the small gap (approximately $0.3 \mathrm{~mm}$ ) remaining between the galvanized plates (upper plates of welding) and the reinforcement plate (lower plate of welding). This is due to the fixture circumstance and the deficiency of clamping force [37]. Moreover, this circumstance has the same results in tests 4,5 , and 8 wherein the lack of clamping force affects the welding quality. Also, this problem is observed in test 7 but in a different location, a range of $1000 \mu \mathrm{m}$ weld depth. There is a critical region with red color because of a high cooling rate in the HAZ region and less hardness distribution close to $1500 \mu \mathrm{m}$ weld depth. The hardness profile in this test is generally not well distributed. However, it demonstrates that decreasing welding speed, gap, and increasing clamping force reduces void areas.

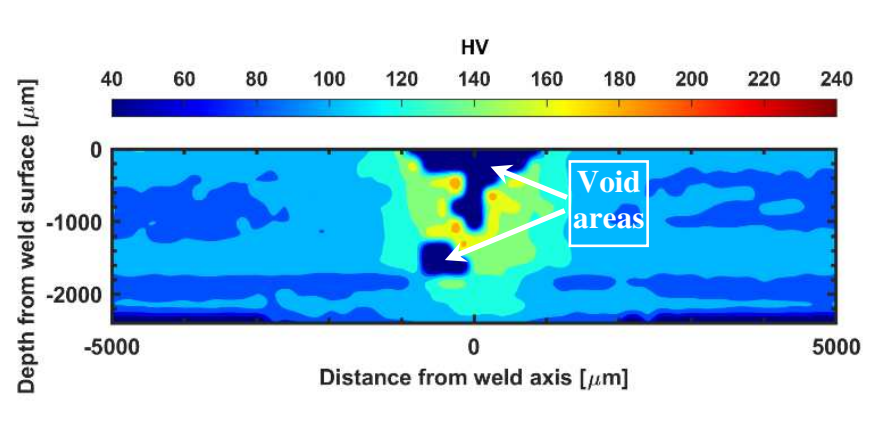

(a)

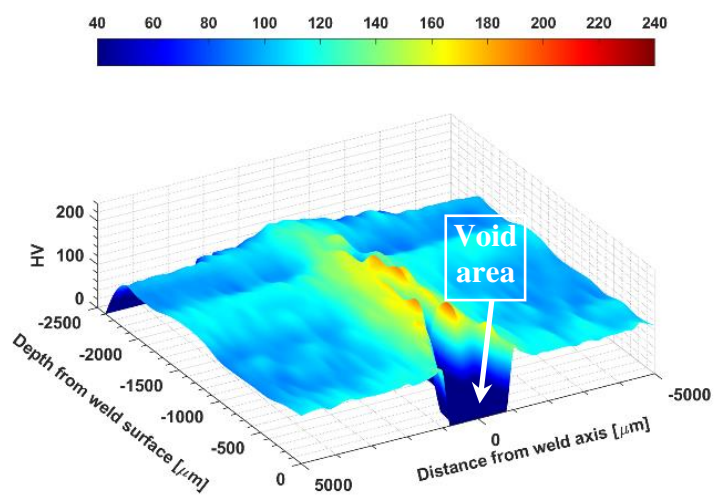

(b)

Figure 4.Hardness profile of test $1(P=1200 \mathrm{~W}, V=13 \mathrm{~mm} / \mathrm{s}, f=150 \mathrm{~Hz}$ and $\mathrm{g}=0.55 \mathrm{~mm})$ a) contour plot $b)$ $3 D$ surface plot. 


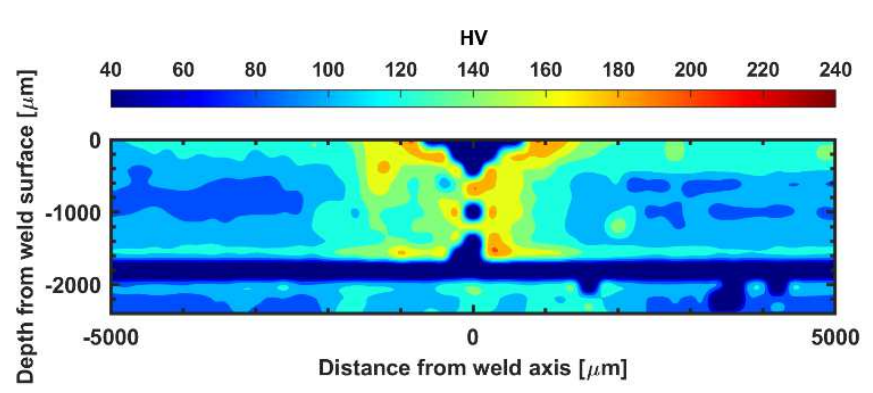

(a)

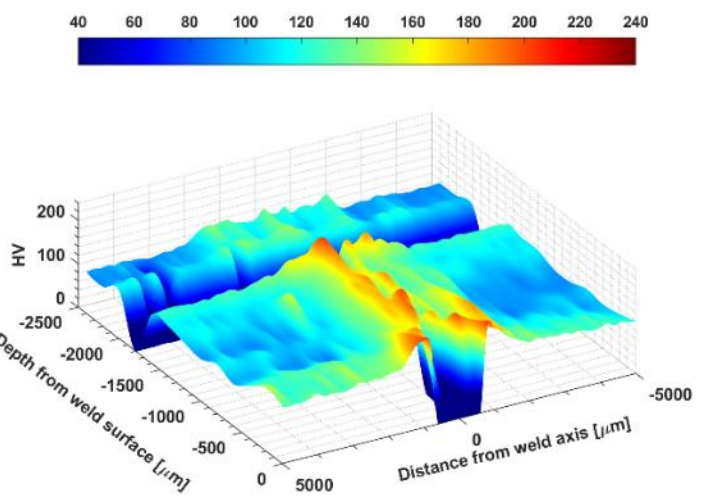

(b)

Figure 5. Hardness profile of test $2(P=1200 \mathrm{~W}, \mathrm{~V}=10 \mathrm{~mm} / \mathrm{s}, f=175 \mathrm{~Hz}$ and $\mathrm{g}=0.35 \mathrm{~mm})$ a) contour plot $b)$ $3 D$ surface plot.

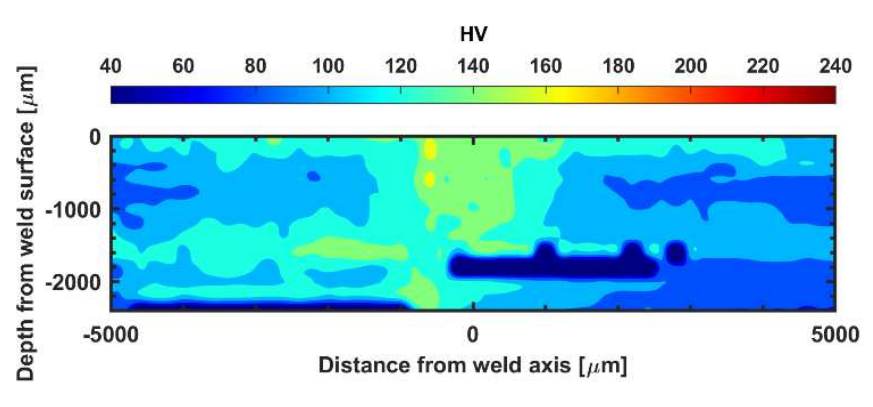

(a)

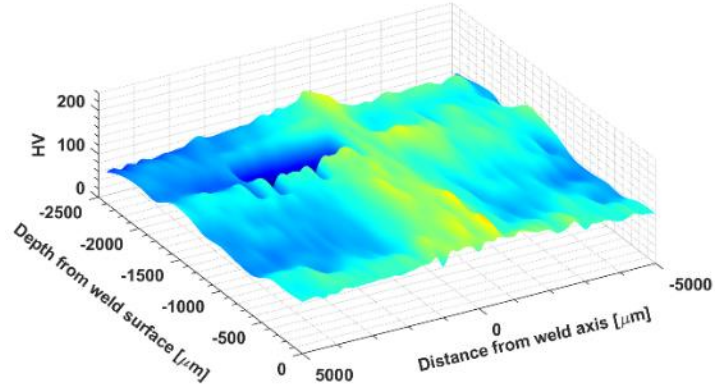

(b)

Figure 6. Hardness profile of test $3(P=1200 \mathrm{~W}, \mathrm{~V}=7 \mathrm{~mm} / \mathrm{s}, f=200 \mathrm{~Hz}$ and, $g=0.15 \mathrm{~mm})$ a) contour plot $b)$ $3 D$ surface plot.

Increasing the welding power up to $1400 \mathrm{~W}$ in tests 4,5 , and 6 , the hardness profiles are respectively illustrated in Figure 7, Figure 8, and Figure 9. It can be observed in Figure 8 that a representative hardness distribution is achieved wherein the HAZ hardness distribution of $110 \mathrm{HV}$ to $170 \mathrm{HV}$ in the middle of the weld seam is noticed. However, some unavoidable porosities are observed in the upper weld depth band (0$250 \mu \mathrm{m})$ and lower weld depth band $(1500 \mu \mathrm{m}-2000 \mu \mathrm{m})$. Based on Figure 9, there is a narrow vertical porosity in the $1500 \mu \mathrm{m}-2000 \mu \mathrm{m}$ weld depth as well as horizontal voids on the surface of welding. In other respects, a well representative hardness distribution concerning HAZ of welding can be observed in this test. In fact, the hardness in HAZ (yellow and orange regions) is higher than the base metal, which confirms that laser welding of galvanized steel sheets does not soften HAZ. Investigating the hardness distributions reveals that the heating and cooling rate are fast enough during laser welding, which produces rationale layers and generates a narrow incomplete annealed zone of HAZ. 


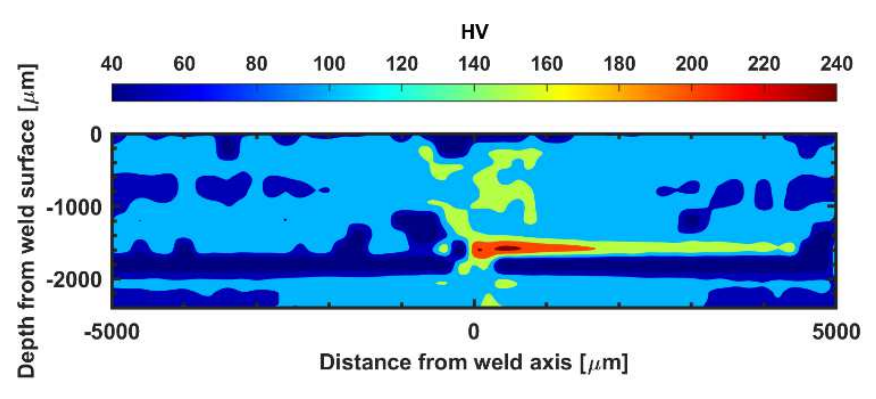

(a)

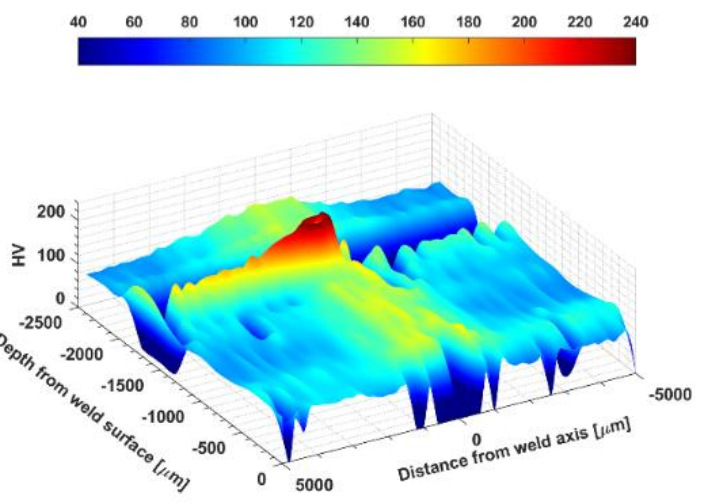

(b)

Figure 7. Hardness profile of test $4(P=1400 \mathrm{~W}, V=13 \mathrm{~mm} / \mathrm{s}, f=175 \mathrm{~Hz}$, and $\mathrm{g}=0.15 \mathrm{~mm})$ a) contour plot $b)$ $3 D$ surface plot.

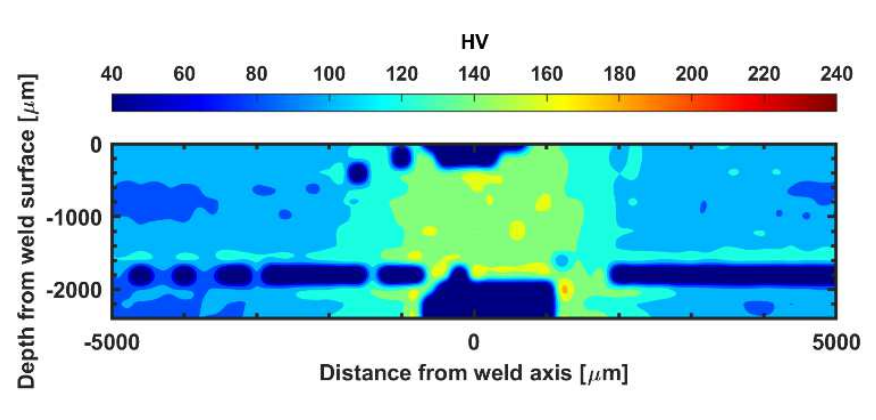

(a)

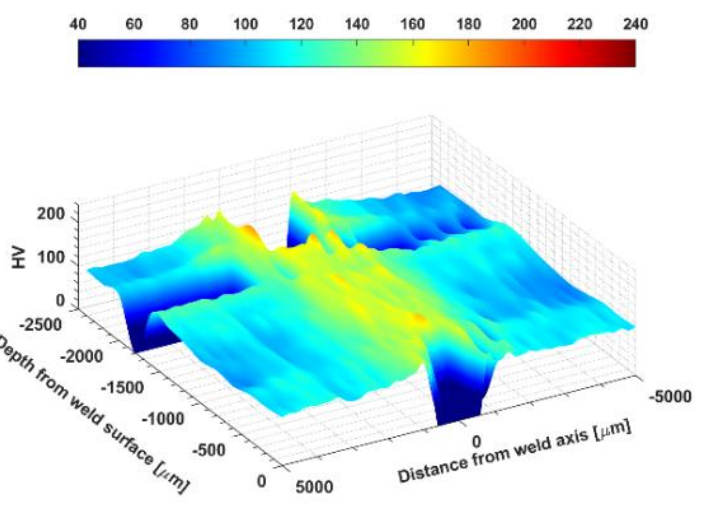

(b)

Figure 8. Hardness profile of test $5(P=1400 \mathrm{~W}, \mathrm{~V}=10 \mathrm{~mm} / \mathrm{s}, f=200 \mathrm{~Hz}$, and $\mathrm{g}=0.55 \mathrm{~mm})$ a) contour plot $\mathrm{b})$ $3 D$ surface plot.

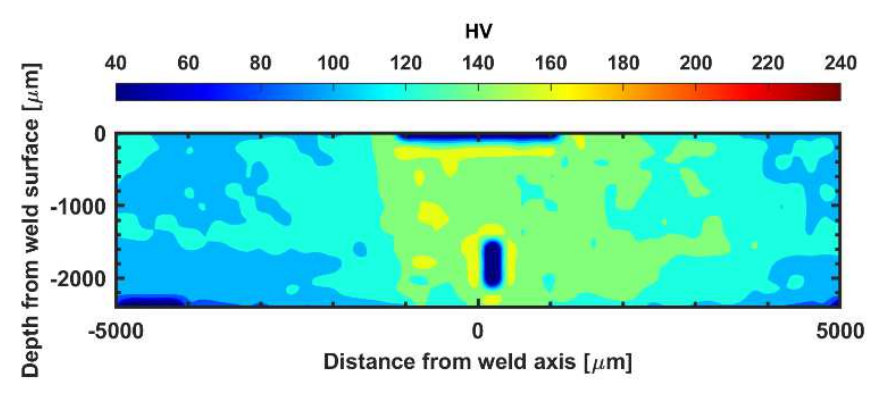

(a)

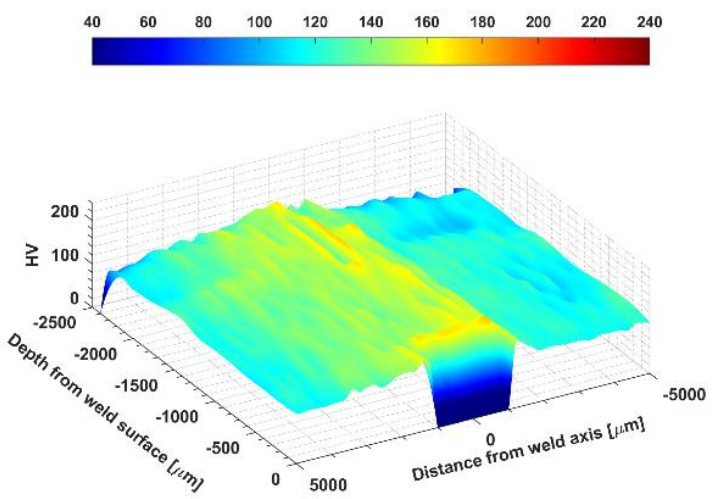

(b)

Figure 9. Hardness profile of test $6(P=1400 \mathrm{~W}, V=7 \mathrm{~mm} / \mathrm{s}, f=150 \mathrm{~Hz}$, and $\mathrm{g}=0.35 \mathrm{~mm})$ a) contour plot $b)$ $3 D$ surface plot. 
Increasing welding speed in laser-welded galvanized parts decreases the penetration depth and welding width, whereby the porosity formation is quite possible [38]-[40]. Conversely, reducing the welding speed would significantly increase weld width but a slight increase in penetration depth. Scanning frequency as another input parameter plays a crucial role in the hardness distribution at the fusion zone (FZ). Scanning frequency makes sound welds with refined grain and generates the equated grains by stirring. However, due to the hydrodynamic forces in the melting pool, temperature gradient, and Marangoni effect during the melt pool formation, this factor has an optimum level. The power is increased to $1600 \mathrm{~W}$ in Figure 10, Figure 11, and Figure 12. Figure 10 shows the arbitrary porosities in a wide range of weld depth and the generation of brittle phase (high hardness zones) in the weld seam. In addition, we can detect some porosities and voids on the surface of weld seam. Based on Figure 11, it could be concluded that this parameters setup would not lead to proper welding result, either with respect to the hardness distribution or to porosities and void areas criteria. Figure 12 also presents voids in the middle and the surface of weld seam.

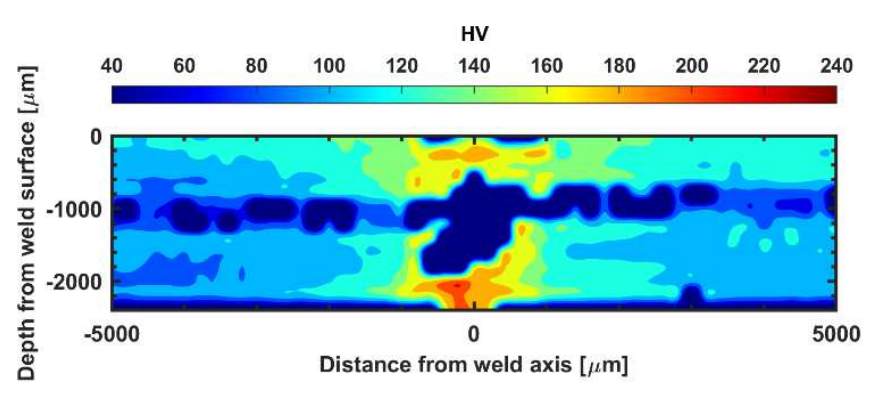

(a)

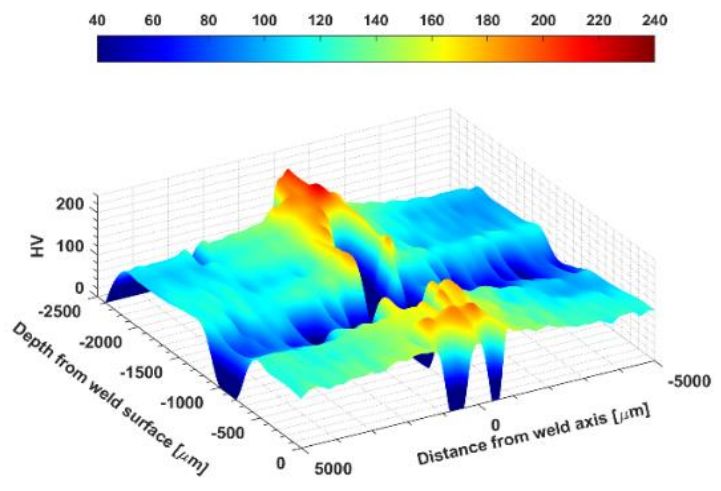

(b)

Figure 10. Hardness profile of test $7(P=1600 \mathrm{~W}, V=13 \mathrm{~mm} / \mathrm{s}, f=200 \mathrm{~Hz}$ and, $g=0.35 \mathrm{~mm})$ a) contour plot b) $3 D$ surface plot.

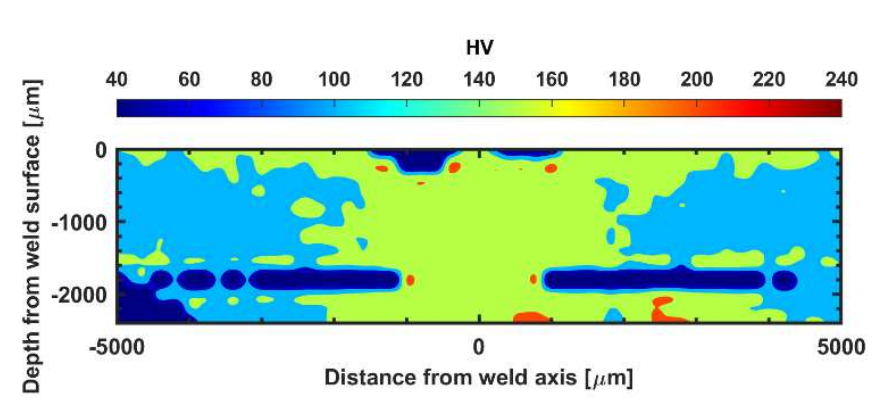

(a)

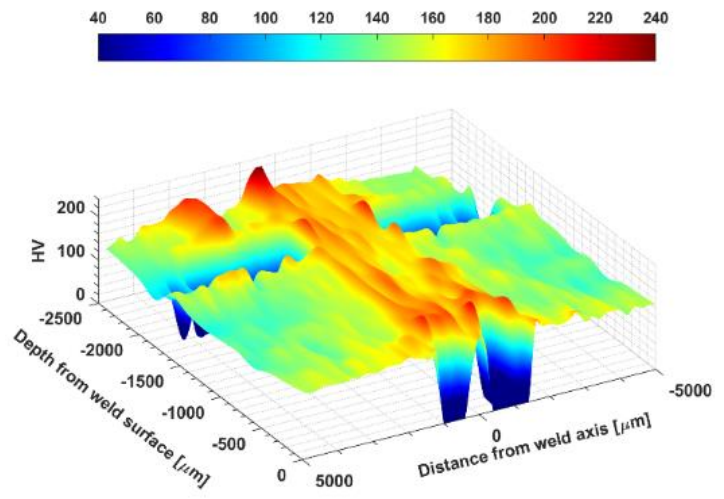

(b)

Figure 11. Hardness profile of test $8(P=1600 \mathrm{~W}, \mathrm{~V}=10 \mathrm{~mm} / \mathrm{s}, f=150 \mathrm{~Hz}, g=0.15 \mathrm{~mm})$ a) contour plot $b) 3 D$ surface plot. 


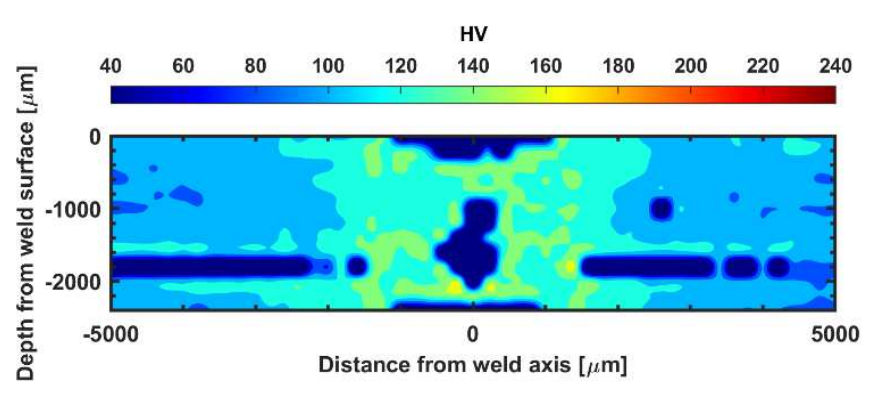

(a)

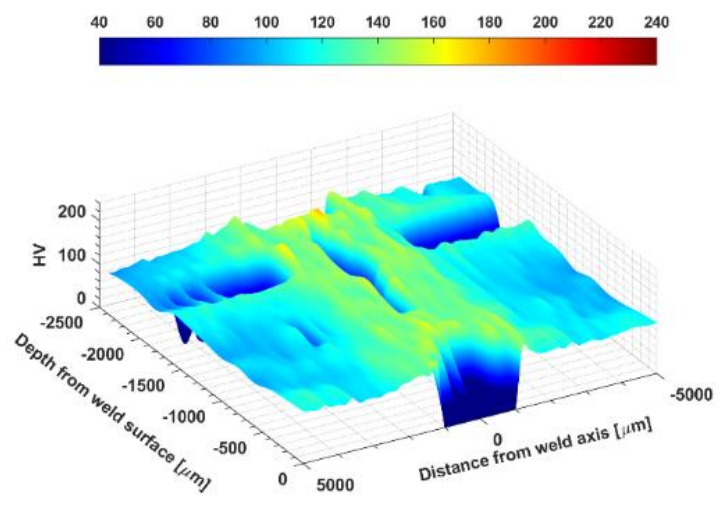

(b)

Figure 12. Hardness profile of test $9(P=1600 \mathrm{~W}, V=7 \mathrm{~mm} / \mathrm{s}, f=175 \mathrm{~Hz}$, and $\mathrm{g}=0.55 \mathrm{~mm})$ a) contour plot $b)$ $3 D$ surface plot.

In general, there is an optimum setup to achieve a proper laser-welded joint quality. In this regard, finding the optimum setup and interaction of process parameters is a vital point in the welding of galvanized sheets. Too fast welding speed parameters lead to short solidification time, which is in favor of pores formation in welding joints and welding defects because of zinc evaporation during a welding operation. Simultaneously, once the workpiece is heated up, the moisture in the atmosphere or adhered to the surface of the plate is broken down into hydrogen and will generate voids and pores in the welding region [38]. Additionally, once the laser power is set at a constant level, the welding speed should be adjusted to obtain the required penetration depth. In such circumstance, if the welding speed is adjusted to the low level, the weld surface subsidence appears because of extreme evaporation of welded material, then the welding joints extends, and such defects as pores are simply formed in the welding zone. All in all, the optimum inputs set up (welding power: $1200 \mathrm{~W}$, welding speed: $7 \mathrm{~mm} / \mathrm{s}$, scanning frequency: $200 \mathrm{~Hz}$, Gap: $0.15 \mathrm{~mm}$ ) for test 3 presents an appropriate HAZ distribution and also fewer porosities in the welding region. The faulty and defective welding results are also observed in test 7.

\subsection{Welding geometry inspection}

In this part, the area of pores detected by image processing of the laser-welded galvanized steel and then are measured (

Table 6). The cross-section geometry of welding is visualized using Clemex Vision ${ }^{\mathrm{TM}}$ to measure the weld depth and weld width. The presence of voids and porosities is also verified by measuring the voids area based on automatic porosity detection using image processing of weld cross-section under a microscope. The microstructure of submitted welded plates is viewed at $100 \mathrm{X}$ and image processing is investigated by Clemex Vision ${ }^{\mathrm{TM}}$ software. Images automatically stitch multiple areas to create continuous tailored images of the whole welding sample which can then be analyzed and saved (Figure 13) [41]. An analysis of variance and the development of a linear regression model are then carried out, which led to models predicting weld width, and voids area with respect to laser-welding process parameters. The welding geometry considered in this study includes the pores and voids in the welding cross-section and the average width of welding, which is estimated at half the depth of welding. A welding geometry and defect regions of a weld seam are illustrated in Figure 14. 
Table 6. Combination of laser-welding process parameters (input factors) versus welding width and porosities area (output responses).

\begin{tabular}{ccccc|cc}
\hline \multirow{2}{*}{$\begin{array}{c}\text { Tests } \\
\text { No. }\end{array}$} & \multicolumn{4}{c|}{ Factors } & \multicolumn{2}{c}{ Responses } \\
\cline { 2 - 7 } $\mathbf{1}$ & 1200 & 13 & 150 & 0.55 & 2.095 & 699610 \\
$\mathbf{2}$ & 1200 & 10 & 175 & 0.35 & 1.592 & 392952 \\
$\mathbf{3}$ & 1200 & 7 & 200 & 0.15 & 1.734 & 77335 \\
$\mathbf{4}$ & 1400 & 13 & 175 & 0.15 & 2.604 & 128286 \\
$\mathbf{5}$ & 1400 & 10 & 200 & 0.55 & 2.140 & 1169830 \\
$\mathbf{6}$ & 1400 & 7 & 150 & 0.35 & 2.844 & 1044454 \\
$\mathbf{7}$ & 1600 & 13 & 200 & 0.35 & 2.066 & 834279 \\
$\mathbf{8}$ & 1600 & 10 & 150 & 0.15 & 2.717 & 293712 \\
$\mathbf{9}$ & 1600 & 7 & 175 & 0.55 & 3.248 & 1257601 \\
\hline
\end{tabular}
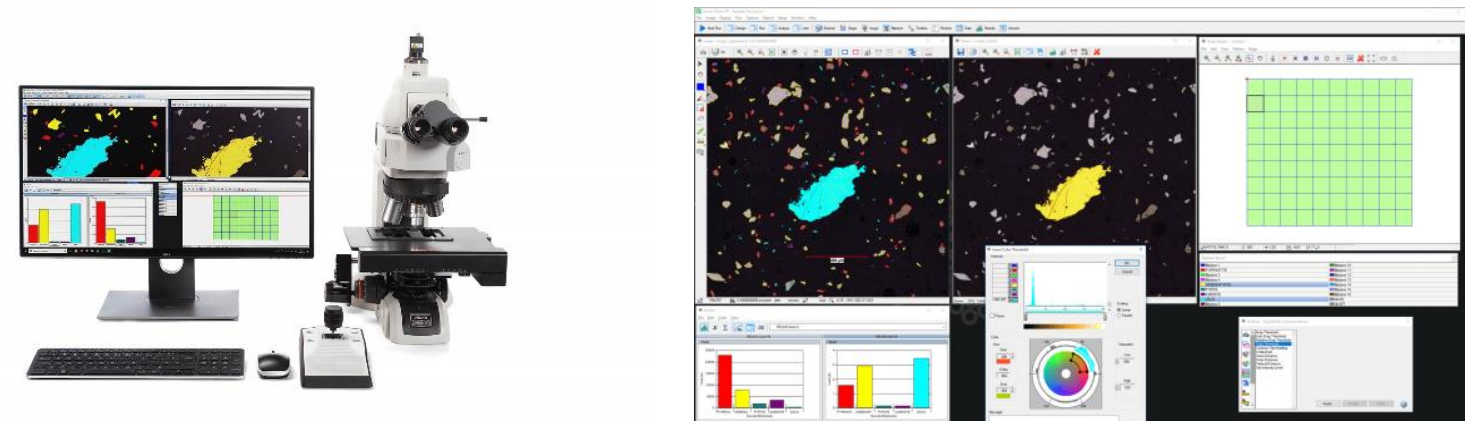

Figure 13. Porosity analysis using a micro-indentation matrix pattern over a welding cross-section [41].

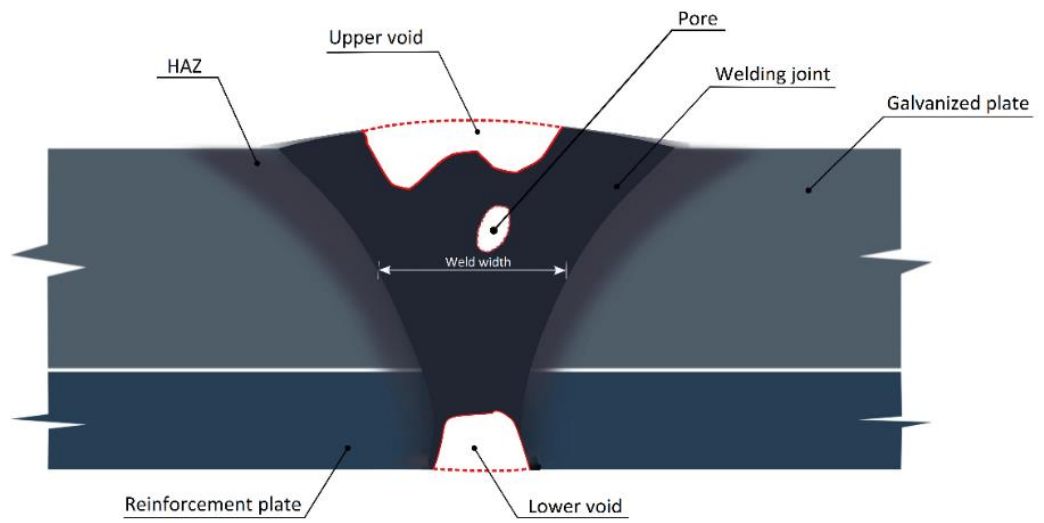

Figure 14. Geometric characteristics of welding and some welding defects schema [37]. 


\subsection{Statistical Analysis}

Analysis of variance (ANOVA) is a powerful statistical method to evaluate the main effect of factors and their interactions with respect to the responses of experimental data [42]. In this case, the design is crossed, not nested, and the premise is that factors are fixed, not random. In this approach, some terms such as pvalues, lack of fit, and $\mathrm{R}$-squared $\left(\mathrm{R}^{2}\right)$ values for comparing models are crucial to define interactions and influences of process parameters. F-values imply that whether ANOVA null hypothesis, the effect of parameter on the response is not significant, can be rejected. ANOVA analysis is performed using stepwise progression and non-hierarchical mode. A linear regression model is then developed based on main process parameters (factors) and their interaction to predict welding geometries of laser-welded galvanized plates in weld cross-section such as weld widths (WW) and weld voids (WV). In the following sections, the influence of process parameters and the contribution percentage of each factor as well as factors interactions with respect to each response (WW and WV) is discussed.

\subsubsection{Weld width}

Regarding the weld geometry and penetration, it would be necessary to investigate the interaction of input factors on the welding geometry and define the optimum setup to achieve the best factor range. Due to the nature of welding processes, the relationship between HAZ distribution and weld width is a critical problem in welding technology. Laser beam welding not only provides a narrow weld seam but also presents a welldistributed HAZ. Regarding the analysis of weld seam geometry, thermal distribution, power range, and keyhole formation take a leading role during welding processes. To this end, keyhole analysis is essential to define the weld width. In addition, thermocapillary flow in the weld pool (surface tension force and buoyancy force) could be affected by the weld seam during laser welding [43]. The characterizing spatial and temporal distribution of laser energy on the surface of a workpiece is described as following [44]:

$P_{d}=\frac{4 P}{D^{2}{ }_{B}}$

$t_{i}=\frac{v}{D_{B}}$

$E_{S P}=P_{d} \times t_{i} \times \frac{\pi D_{B}^{2}}{4}$

$E_{d}=P_{d} \times t_{i}$

Where $P_{d}, t_{i}, E_{S P}, E_{d}, D_{B}$, and $v$ are power density, interaction time, specific point energy, energy density, beam diameter, and welding speed, respectively. Based on Equations 1-4, there is a correlation between weld width and the beam diameter, provided that the interaction time is long enough to allow for sufficient heat conduction [44]. In the same study, the weld bead width is observed to be less with increasing welding speed. In other words, once welding speed is increased beyond optimal conditions, it causes both penetration and weld width to decrease and this instance led to a negative result of increasing out-of-tolerance part numbers.

Here, the influence of welding parameters is evaluated, and a predictive model of mean weld width is established. The effects of parameters on average weld widths are shown in Figure 15, and the ANOVA table for the average weld width predictive model is presented in Table 7. It can be seen from Figure 15 and Table 7 that the most influential parameters are the multiplication of laser beam power and scanning frequency of laser beam $(\mathrm{P} \times \mathrm{f})$ with a $45.35 \%$ effect contribution on the response. Taking into consideration a significance level of $5 \%(\alpha=0.05$, the probability of rejecting the null hypothesis when it is true), only $\mathrm{f}$ and P $\times f$ with p-values of 0.011 and 0.014 have a significant effect on the response. The steep mean vales fluctuation of $\mathrm{P}$ (from 1.8 to 2.7) in Figure 15 implies that $\mathrm{P}$ contributes significantly in the variation of the response, and ANOVA analysis proves that the effect of $\mathrm{P}$ is considered in the interactions with $\mathrm{f}$ and also 
in Error contribution. However, ANOVA analysis confirms the significant effect of $\mathrm{f}$ in which the steep mean fluctuation of $\mathrm{f}$ (from 2.55 to 1.95 ) is presented in Figure 15.
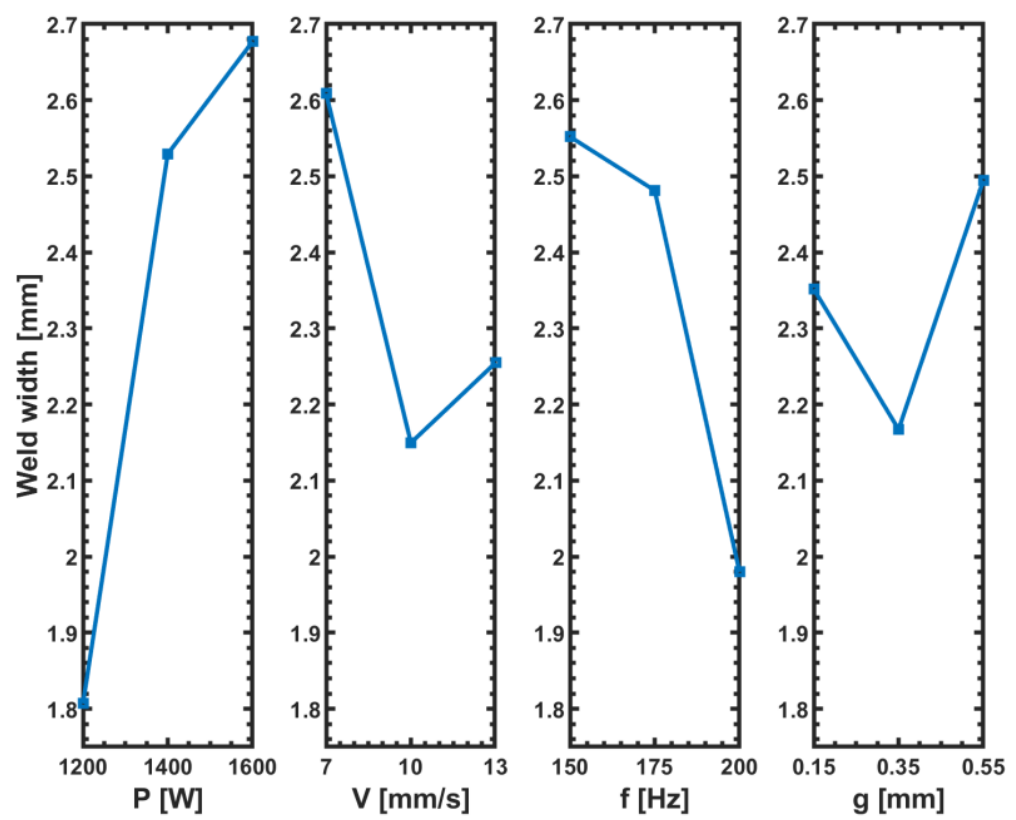

Figure 15. Main effects of parameters on average weld widths.

Table 7. ANOVA table for the average weld width of galvanized laser-welded plates.

\begin{tabular}{ccccccc}
\hline Source & DF & $\begin{array}{c}\text { Sum of } \\
\text { Squares }\end{array}$ & Contribution & $\begin{array}{c}\text { Mean } \\
\text { Squares }\end{array}$ & F-Value & P-Value \\
\hline $\mathrm{f}$ & 1 & 0.4908 & $20.52 \%$ & 1.5740 & 15.56 & 0.011 \\
$\mathrm{P} \times \mathrm{f}$ & 1 & 1.0848 & $45.35 \%$ & 1.3906 & 13.74 & 0.014 \\
$\mathrm{P} \times \mathrm{V} \times \mathrm{f}$ & 1 & 0.3106 & $12.98 \%$ & 0.3106 & 3.07 & 0.140 \\
Error & 5 & 0.5059 & $21.15 \%$ & 0.1012 & & \\
Total & 8 & 2.3921 & $100.00 \%$ & & & \\
\hline
\end{tabular}

The linear regression equation that has led to the predictive modeling of the average weld width (WW) as a function of main effecting welding parameters is as follows:

$$
\begin{gathered}
W W=4.22308-0.02890 \times f+1.60285 \times 10^{-5} \times P \times f \\
+3.07103 \times 10^{-7} \times P \times V \times f
\end{gathered}
$$

Wherein $W W$ is the average width of welding in [mm], $P$ is the laser spot power [W], and $f$ is the laser spot frequency $[\mathrm{Hz}]$. It worth mentioning that $\mathrm{R}$-squared $\left(\mathrm{R}^{2}\right)$, the coefficient of determination, is the proportion of the variance of the predicted dependent variable over the total variations in each experimental test. In other words, $\mathrm{R}^{2}$ is a statistical measure of fit that indicates how much variation of predicted dependent variable is explained by the independent variable(s) in a regression model. In this regard, the best fit is presented by a predicting model with $\mathrm{R}^{2}$ of $100 \%$. The $\mathrm{R}^{2}$ coefficient obtained for the average weld with (WW) regression model is $78.85 \%$, which shows the closeness of the predicted model to experimental 
results. According to Figure 16, the predicted model is verified by the measured average width of welding. Predicted values that agree exactly with measured values would fall on the red line, while the dispersion of these values (blue points) with respect to the red line represents the lack of fitness. Regarding Figure 16, residuals are the differences between experimental values (measured average width of welding of each test) and predicted values. In order to estimate the model's accuracy, the average residual of nine (9) tests is less than $0.5 \mathrm{~mm}$ for weld with, which can confirm the reliability of our predictive model concerning the average weld width of galvanized laser-welded plates.

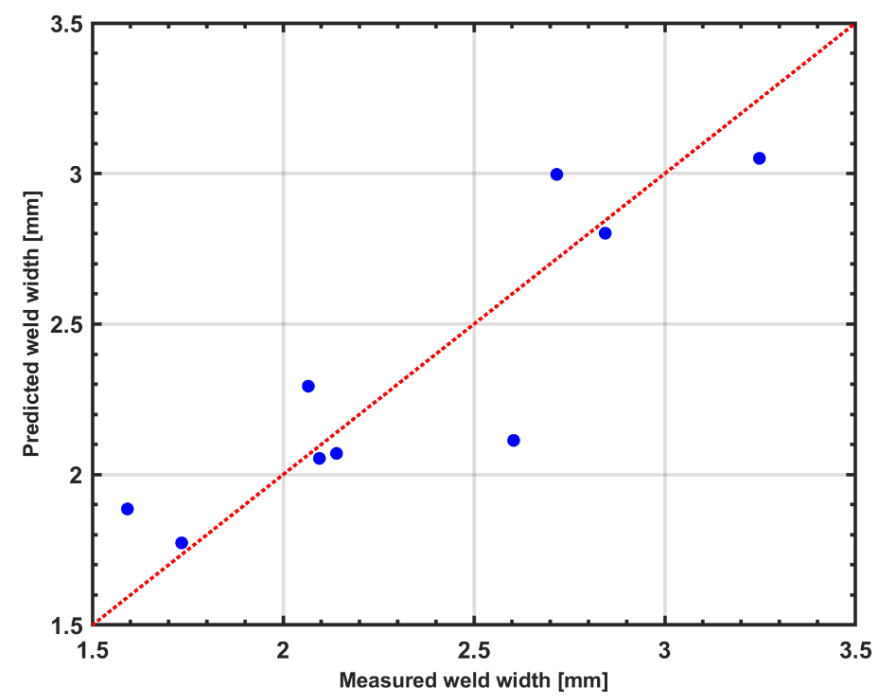

Figure 16. Welding widths measured by experiments versus predicted by regression equations for each experimental test.

\subsubsection{Voids area}

As porosity is a critical defect in the laser welding operation, the second objective function is considered as voids area. In this regard, sources that play a significant role in the formation of porosities are surface contamination or insufficient cleaning and polishing, laser keyhole instability, inert gas shield (high or too low gas flow rate), and surface oxide [45], [46]. Specifically, in aluminum alloy and some coting metals like galvanized steel, porosity can be a particular problem caused by hydrogen and vaporized zinc evolution in the weld metal. Regarding this fact, an exhaustive comprehension of process conditions and factors interaction is important to avoid welding defects. Void detection is essential in industrial production since its consequence on products can lead to catastrophic accidents. Here, voids area in the welding is defined by summing all pore areas (inside welding) and indentations (upper and lower surface of welding). An analysis of the variance (ANOVA) of weld voids is then performed on the results of experimental tests to evaluate the effect of laser welding parameters on the formation of welds voids. Like the previous section, ANOVA is performed using a stepwise and hierarchical model. The Influence of welding parameters on the responses is evaluated, and a predictive model estimating voids area in the welding cross-section is established (Figure 17). The steep mean fluctuation of measured voids area with respect to the variation of gap (g) implies that the effect of this parameter on the response is the most. This hypothesis is also confirmed with ANOVA analysis in Table 8 wherein the p-value of $\mathrm{g}$ is 0.002 , much less than the determined significance level $(\alpha=0.05)$. This rejects the null hypothesis of ANOVA, which states that the effect of the parameter on the response is not significant. 

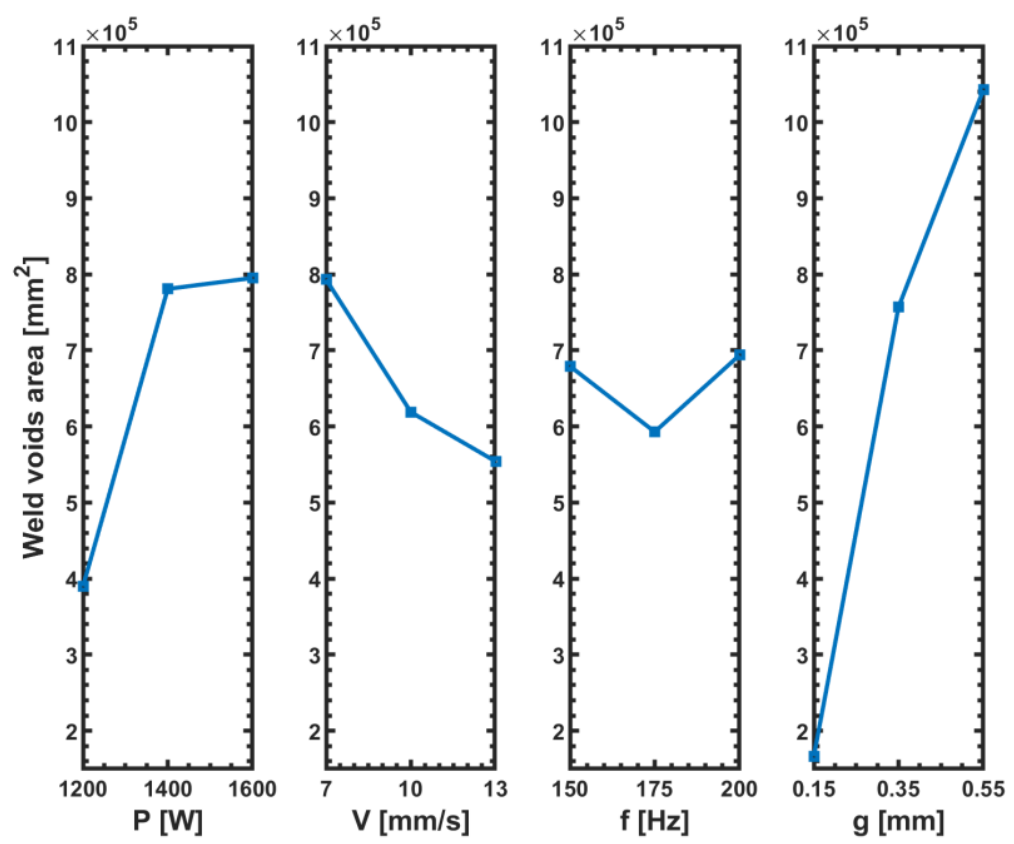

Figure 17. Main effects of parameters on voids area of galvanized laser-welded plates.

Table 8. ANOVA table for voids area of galvanized laser-welded plates.

\begin{tabular}{ccccccc}
\hline Source & DF & $\begin{array}{c}\text { Sum of } \\
\text { Squares }\end{array}$ & Contribution & $\begin{array}{c}\text { Mean } \\
\text { Squares }\end{array}$ & F-Value & P-Value \\
\hline V & 1 & $8.5733 \mathrm{E}+10$ & $5.28 \%$ & $3.38 \mathrm{E}+11$ & 16.09 & 0.016 \\
$\mathrm{f}$ & 1 & 317815704 & $0.02 \%$ & $2.82 \mathrm{E}+11$ & 13.42 & 0.022 \\
$\mathrm{~g}$ & 1 & $1.15 \mathrm{E}+12$ & $70.85 \%$ & $1.15 \mathrm{E}+12$ & 54.83 & 0.002 \\
V $\times \mathrm{f}$ & 1 & $3.03 \mathrm{E}+11$ & $18.68 \%$ & $3.03 \mathrm{E}+11$ & 14.46 & 0.019 \\
Error & 4 & $8.3962 \mathrm{E}+10$ & $5.17 \%$ & $2.099 \mathrm{E}+10$ & & \\
Total & 8 & $1.62 \mathrm{E}+12$ & $100.00 \%$ & & & \\
\hline
\end{tabular}

The linear regression equation as a function of the most significant parameters and their interactions predicting the voids area in laser welding galvanized plates is determined as follows:

$W V=6663529-682555 \times V-36435 \times f+2189757 \times g+3673 \times V \times f$

Where WV is the area of voids in welding cross-section $\left[\mu \mathrm{m}^{2}\right], \mathrm{V}$ is the welding speed $[\mathrm{mm} / \mathrm{s}], \mathrm{f}$ is the scanning frequency of the laser beam $[\mathrm{Hz}]$ and $g$ is the horizontal gap between the main plates $[\mathrm{mm}]$. The $\mathrm{R}$-squared $\left(\mathrm{R}^{2}\right)$ coefficient obtained for this modeling is $94.83 \%$, which sufficiently shows the closeness of the numerical model to measured results. In this regard, Figure 18 presents the variation of measured and predicted voids area for nine (9) tests as well as the residual between these values for each test. A very good agreement is observed in Figure 18 between the predicted model and experimental measurements, wherein the points representing the measured and predicted voids area (blue points) are almost on the red line. It can be observed that predicted voids in test 4 represent some disagreement with the measured value, however, other tests represent an almost excellent agreement between prediction and measurement. 


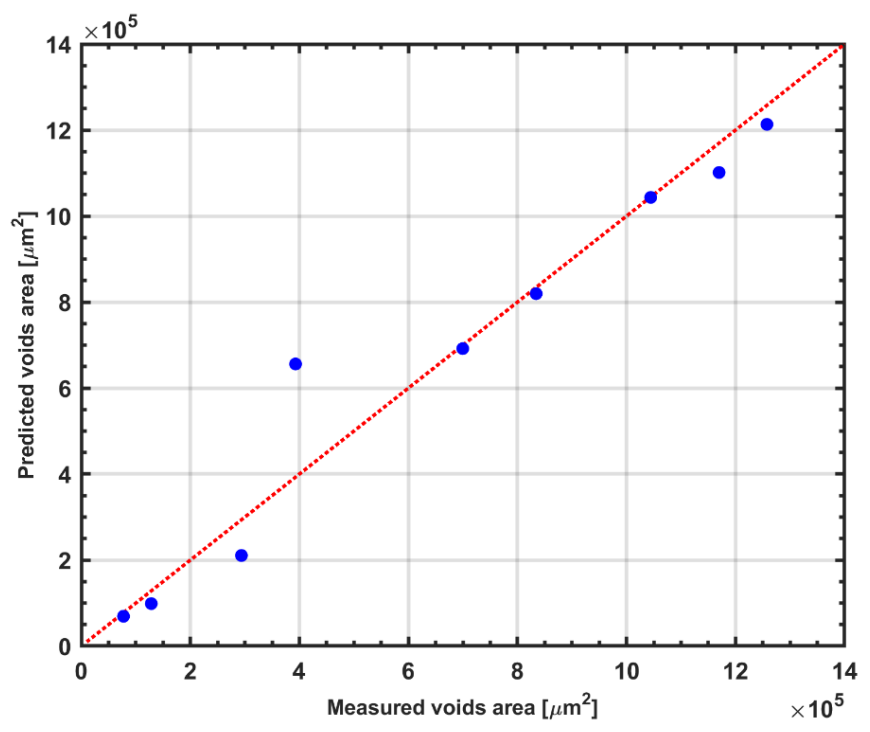

Figure 18. Voids area measured by experiments versus predicted by regression equations for each experimental test.

\subsection{Response surface methodology (RSM)}

Due to the nature of the manufacturing process, several parameters with a diverse level deal within the manufacturing process so that in order to enhance the production quality, it is mandatory to apply DOE systematic strategy and optimizations. From a practical perspective, the optimization task is divided into five main sections, randomization, replication, blocking, orthogonality, factorial experimentation [47]. In optimization, the engineering department seeks to find the best setting for a process regarding factors affecting the process to optimize one or more output responses. In statistics, response surface methodology (RSM) is a gathering of statistical techniques and mathematics that presents graphically the optimization trend of a response based on two explanatory variables [48].

\subsection{Response surface modeling of weld width}

Regarding the interaction of process parameters on weld width, Figure 19 shows the contour plots of process factors interaction on the weld width of galvanized laser-welded plates as an objective function. As illustrated in Figure 19-a, increasing the welding speed from 7 to $13 \mathrm{~mm} / \mathrm{s}$ and decreasing the welding power from 1600 to $1200 \mathrm{~W}$, the weld width is decreased to less than $1.8 \mathrm{~mm}$. On the other hand, by increasing the scanning frequency from 150 to $200 \mathrm{~Hz}$ and reducing the welding power up to $1200 \mathrm{~W}$, the weld width achieves less than $1.6 \mathrm{~mm}$ (Figure 19-b). Furthermore, the minimum value of weld width could be reported at maximum welding speed and scanning frequency $13 \mathrm{~mm} / \mathrm{s}$ and $200 \mathrm{~Hz}$, respectively. It worth mentioning that in each setting, the third factor is adjusted at its mean level. As a result, the interaction between the welding speed and scanning $(\mathrm{V} \times \mathrm{F})$ has a minimum impact on the weld width. 


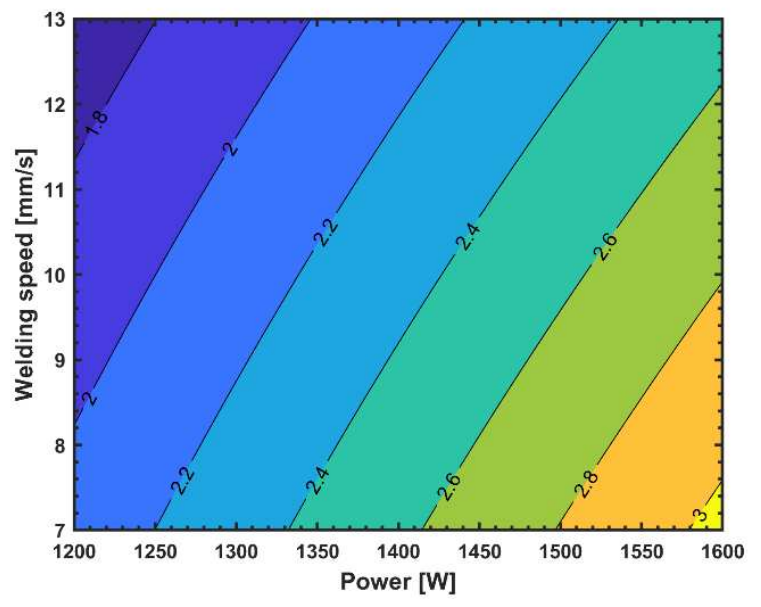

(a)

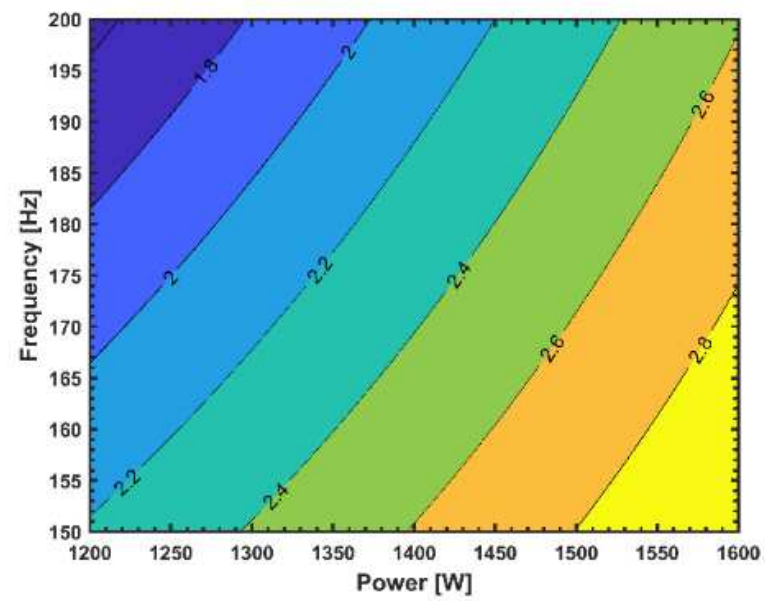

(b)

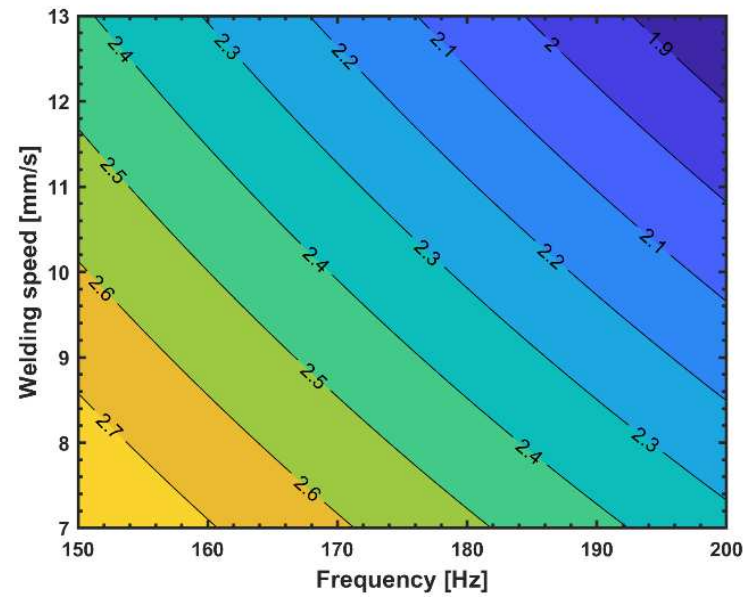

(c)

Figure 19. The contour plots of process factors interactions on the weld width a) power and welding speed $b$ ) power and frequency c) welding speed and frequency.

\subsection{Response surface modeling of voids area}

The response surface of process factors on voids area as the objective function is studied in this section. According to Figure 20-a, the minimum voids appears at a higher welding speed of $13 \mathrm{~mm} / \mathrm{s}$ and a lower scanning frequency of almost $150 \mathrm{~Hz}$. In addition, there is an inverse relationship between the interaction of welding speed and gap (Figure 20-b). The voids formation is governed mostly by frequency than the gap, as demonstrated in Figure 20-c. Thus, increasing the welding speed from 7 to $13 \mathrm{~mm} / \mathrm{s}$, decreasing the gap from 0.55 to $0.15 \mathrm{~mm}$, and decreasing the frequency from 200 to $150 \mathrm{~Hz}$ reduces the formation of porosities and voids in laser welding of galvanized plates. 


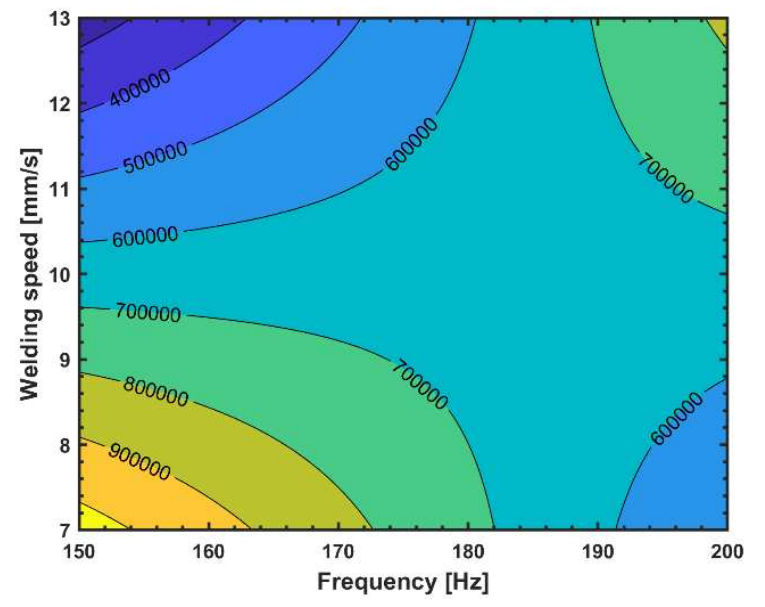

(a)

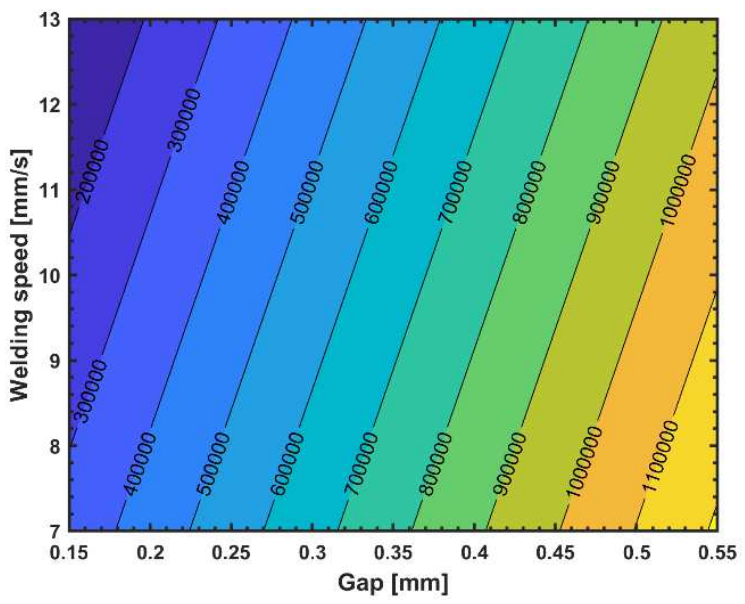

(b)

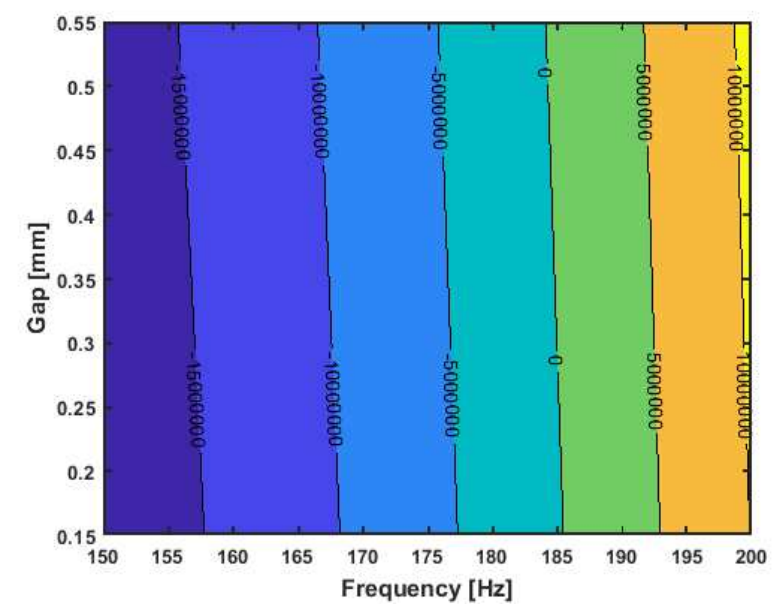

(c)

Figure 20. The contour plots of process factors interaction on the weld voids area a) welding speed and frequency b) welding speed and gap c) frequency and gap

\section{Conclusions}

In this article, the effect of laser welding parameters on the hardness profile, using hardness mapping analyses, and welding geometry of galvanized steel plates are investigated. Analyzing Ishikawa's diagram for laser welding of galvanized plates, the most influential parameters such as laser power $(\mathrm{P})$, welding speed (V), scanning frequency (f), and horizontal gaps between butt-welded plates ( $\mathrm{g}$ ) are determined. To optimize the experimental efforts, the design of experiments approach (using Taguchi method) is applied, and nine (9) tests are developed to study the interactions of process parameters based on statistical analyses. In the first place, an innovative method of weld defect detection is performed by a pattern matrix using micro-indentation hardness experiment of weld seam at its cross-section. The hardness profile of weld in each test is qualitatively analyzed the effect of process parameters on the formation of weld defects. In this regard, the optimum factors set up, welding power at $1200 \mathrm{~W}$, welding speed at $7 \mathrm{~mm} / \mathrm{s}$, scanning frequency at $200 \mathrm{~Hz}$, and the gap at $0.15 \mathrm{~mm}$ in test 3 present the adequate $\mathrm{HAZ}$ distribution and also fewer porosities in the welding region. The worst case of these experimentations is noticed in test 7 . In the second place, the most influencing process parameters and their interactions with respect to welding geometry are determined based on analysis of variance (ANOVA). To this end, weld width and voids area are measured under a 
microscope. The regression equation of these objective functions demonstrates that increasing the laser welding speed from 7 to $13 \mathrm{~mm} / \mathrm{s}$, decreasing the gap from 0.55 to $0.15 \mathrm{~mm}$, and decreasing the frequency to $150 \mathrm{~Hz}$, reduces the portability of voids formation. The most influential parameter in welding width at its cross-section is the interaction of laser beam power and scanning frequency of the laser beam $(\mathrm{P} \times \mathrm{f})$ with a $45.35 \%$ contribution in the response. Regarding the void area, the gap between welding plates ( $\mathrm{g}$ ) has the most significant impact on the porosity's formation with a $70.85 \%$ contribution in the response.

Although the results of this study are promising, the research can be extended to apply the method on a more extensive range of parameter variation and multi-objective optimization using artificial intelligence (ANN). The validation of our developed model can also be performed by testing the laser welding process of galvanized plates in the range of parameters' variation. Finally, the clamping effect based on clamping force measurement can be added to the welding defect analyses.

\section{Ethical Approval}

This article does not involve human or animal participation or data, therefore ethics approval is not applicable.

\section{Consent to Participate}

This article does not involve human or animal participation or data, therefore consent to participate is not applicable.

\section{Consent to Publish}

This article does not involve human or animal participation or data, therefore consent to publication is not applicable.

\section{Authors Contributions}

The authors' contributions are as following: Noureddine Barka and Vincent Blériot Feujofack Kemda conceived, planned, and carried out the experiments; Sasan Sattarpanah Karganroudi and Admad aminzadeh contributed to the measurement interpretation, visualization, and analyses of results. Sasan Sattarpanah Karganroudi took the lead in writing the manuscript and Admad aminzadeh contributed actively in writing the manuscript; all authors provided critical feedback and helped shape the research, analysis, and manuscript.

\section{Funding}

This work was supported by the Natural Sciences and Engineering Research Council of Canada (NSERC) Discovery Grants Program [grant number RGPIN-2015-05978] and Fonds de recherche du Québec - Nature et technologies (FRQNT) [grant number 2020-CO-275264].

\section{Competing Interests}

The authors declare that there are no conflicts of interest/competing interests concerning this paper. In this regard, they have no known competing financial interests or personal relationships that could have appeared to influence the work reported in this paper.

\section{Availability of data and materials}

All data, material, and codes used in this paper are available.

\section{References}

[1] S. Yeomans, Galvanized steel reinforcement in concrete. Elsevier, 2004. 
[2] B. Eker and E. Yuksel, "Solutions to corrosion caused by agricultural chemicals," Trakia J. Sci., vol. 3, no. 7, pp. 1-6, 2005.

[3] S. Aich and J. Nayak, "Design and fabrication of a solar portable refrigerator," Mater. Today Proc., 2020 .

[4] V. Colla, S. Cateni, A. Maddaloni, and A. Vignali, "A Modular Machine-Learning-Based Approach to Improve Tensile Properties Uniformity Along Hot Dip Galvanized Steel Strips for Automotive Applications," Metals (Basel)., vol. 10, no. 7, p. 923, 2020.

[5] A. Aminzadeh, A. Parvizi, R. Safdarian, and D. Rahmatabadi, "Comparison between laser beam and gas tungsten arc tailored welded blanks via deep drawing," Proc. Inst. Mech. Eng. Part B J. Eng. Manuf., 2020, doi: 10.1177/0954405420962391.

[6] S. A. Idd, "Method and system for construction and building." Google Patents, 2020.

[7] S. I. Ahmad, M. S. Alam, and M. J. Alam, "Structural and Life-Cycle Economic Feasibility of Rooftop Low-Height Bamboo Telecom Tower Considering a Case Study from Bangladesh," Pract. Period. Struct. Des. Constr., vol. 25, no. 3, p. 5020007, 2020.

[8] P. Krupicz, "Influence of Hot-Dip Galvanizing on Mechanical Properties of Pressure-Locked Gratings," in The 10th International Conference on Engineering, Project, and Production Management, 2020, pp. 523-535.

[9] F. Behnam and others, "Influence of hot dip galvanizing on fatigue behavior of welded steel joints," 2019.

[10] C. Allely, P. Bertho, A. Chakraborty, and H. Ghassemi-armaki, "A method for the manufacturing of liquid metal embrittlement resistant galvannealed steel sheet." 2020.

[11] A. Kaleva et al., "Formation of corrosion products on zinc in wet supercritical and subcritical CO2: In-situ spectroscopic study," Corros. Sci., vol. 174, p. 108850, 2020.

[12] A. Aminzadeh, A. Parvizi, and M. Moradi, "Multi-objective topology optimization of deep drawing dissimilar tailor laser welded blanks; experimental and finite element investigation," Opt. Laser Technol., vol. 125, 2020, doi: 10.1016/j.optlastec.2019.106029.

[13] A. K. Sinha and A. Anand, "Development of an alternative for corrosive resistant galvanized steel compatible for laser welding," Mater. Today Proc., 2020.

[14] Y. Song, X. Li, C. Hu, R. Xia, A. Zou, and X. Tang, "Design of semiconductor laser multi-point beam based on laser welding of galvanized sheet," in Advanced Laser Processing and Manufacturing IV, 2020, vol. 11546, p. 1154605.

[15] X. Li, S. Lawson, Y. Zhou, and F. Goodwin, "Novel technique for laser lap welding of zinc coated sheet steels," J. Laser Appl., vol. 19, no. 4, pp. 259-264, 2007.

[16] R. Akhter, "Laser welding of zinc coated steel," University of London, 1990.

[17] F. Kong, J. Ma, B. Carlson, and R. Kovacevic, "Real-time monitoring of laser welding of galvanized high strength steel in lap joint configuration," Opt. Laser Technol., vol. 44, no. 7, pp. 2186-2196, 2012.

[18] H. Zapf, M. Höfemann, and C. Emmelmann, "Laser welding of additively manufactured medium manganese steel alloy with conventionally manufactured dual-phase steel," Procedia CIRP, vol. 94, pp. 655-660, 2020.

[19] Q. Zhang et al., "Microstructure and Properties of an Al 6061/Galvanized Plate Fabricated by CMT Welding," J. Wuhan Univ. Technol. Sci. Ed., vol. 35, no. 5, pp. 937-945, 2020.

[20] J. Luo et al., "Microstructure and tensile properties of the different thickness ASSAPH440 high strength steel/DC52D+ ZF45 galvanized cold rolled sheet dissimilar metal welding joint by CO 2 laser welding for automobile manufacturing.," Mater. Res. Express, 2020.

[21] W. Chen, P. Ackerson, and P. Molian, "CO2 laser welding of galvanized steel sheets using vent holes," Mater. Des., vol. 30, no. 2, pp. 245-251, 2009.

[22] M. S. Khan, M. H. Razmpoosh, E. Biro, and Y. Zhou, "A review on the laser welding of coated 22MnB5 press-hardened steel and its impact on the production of tailor-welded blanks," Sci. Technol. Weld. Join., pp. 1-21, 2020. 
[23] W. Cai, J. Wang, P. Jiang, L. Cao, G. Mi, and Q. Zhou, "Application of sensing techniques and artificial intelligence-based methods to laser welding real-time monitoring: A critical review of recent literature," J. Manuf. Syst., vol. 57, pp. 1-18, 2020.

[24] S. H. Lee, J. Mazumder, J. Park, and S. Kim, "Ranked Feature-Based Laser Material Processing Monitoring and Defect Diagnosis Using k-NN and SVM," J. Manuf. Process., vol. 55, pp. 307-316, 2020.

[25] H. Xia, W. Tao, L. Li, C. Tan, K. Zhang, and N. Ma, "Effect of laser beam models on laser welding-brazing Al to steel," Opt. Laser Technol., vol. 122, p. 105845, 2020.

[26] S. Deng, R. Yuan, X. Tang, and F. Lu, "Migration behavior of IMC layer in twin-spot laser weldingbrazing of aluminum to steel," Mater. Des., vol. 188, p. 108489, 2020.

[27] M. Mohammadpour et al., "Influence of laser beam inclination angle on galvanized steel laser braze quality," Opt. Laser Technol., vol. 129, p. 106303, 2020.

[28] Y. Zhu, H.-P. Wang, Y. Wang, Y. Hao, B. E. Carlson, and F. Lu, "Formation mechanism of liquid metal embrittlement in laser lap welding of zinc-coated GEN3 steels," Mater. Sci. Eng. A, p. 140229, 2020.

[29] A. G. Kalashami, C. DiGiovanni, M. H. Razmpoosh, F. Goodwin, and N. Y. Zhou, "The effect of silicon content on liquid-metal-embrittlement susceptibility in resistance spot welding of galvanized dualphase steel," J. Manuf. Process., vol. 57, pp. 370-379, 2020.

[30] L. Luca and T. O. Luca, "Ishikawa diagram applied to identify causes which determines bearings defects from car wheels," in IOP Conference Series: Materials Science and Engineering, 2019, vol. 564, no. 1, p. 12093.

[31] S. V Kuryntsev and A. K. Gilmutdinov, "The effect of laser beam wobbling mode in welding process for structural steels," Int. J. Adv. Manuf. Technol., vol. 81, no. 9, pp. 1683-1691, 2015.

[32] E. Broitman, "Indentation hardness measurements at macro-, micro-, and nanoscale: a critical overview," Tribol. Lett., vol. 65, no. 1, p. 23, 2017.

[33] A. A653/A653M-11, "Standard Specification for Steel Sheet, Zinc-Coated (Galvanized) or ZincIron Alloy-Coated (Galvan-nealed) by the Hot-Dip Process." ASTM International West Conshohocken, PA, 2011.

[34] D. ASTM, “A36/A36M-08--Standard Specification for Carbon Structural Steel.”

[35] A. S. for Testing and Materials, Standard Practice for Instrumented Indentation Testing: E254607. ASTM International, 2007.

[36] A. Standard, "E384, Standard test method for microindentation hardness of materials," West Conshohocken, PA ASTM Int., 2000.

[37] S. S. Karganroudi, V. B. F. Kemda, and N. Barka, "A novel method of identifying porosity during laser welding of galvanized steels using microhardness pattern matrix," Manuf. Lett., vol. 25, pp. 98-101, 2020.

[38] L. Mei, G. Chen, X. Jin, Y. Zhang, and Q. Wu, "Research on laser welding of high-strength galvanized automobile steel sheets," Opt. Lasers Eng., vol. 47, no. 11, pp. 1117-1124, 2009.

[39] S. Iqbal, M. M. S. Gualini, and A. ur Rehman, "Dual beam method for laser welding of galvanized steel: Experimentation and prospects," Opt. Laser Technol., vol. 42, no. 1, pp. 93-98, 2010.

[40] Y. Zhao, Y. Zhang, W. Hu, and X. Lai, "Optimization of laser welding thin-gage galvanized steel via response surface methodology," Opt. Lasers Eng., vol. 50, no. 9, pp. 1267-1273, 2012.

[41] P. E. Clemex Vision, "Clemex intelligent microscopy, Quebec, Canada.".

[42] M. Moradi, M. K. Moghadam, and M. Shamsborhan, "The Synergic Effects of FDM 3D Printing Parameters on Mechanical Behaviors of Bronze Poly Lactic Acid Composites," 2020, doi: 10.3390/jcs4010017.

[43] C. Lampa, "Laser welding: energy redistribution and weld geometry," Luleåtekniska universitet, 1997.

[44] W. A. Ayoola, W. J. Suder, and S. W. Williams, "Parameters controlling weld bead profile in conduction laser welding," J. Mater. Process. Technol., vol. 249, pp. 522-530, 2017. 
[45] M.-A. Rezaei and H. Naffakh-Moosavy, "The effect of pre-cold treatment on microstructure, weldability and mechanical properties in laser welding of superalloys," J. Manuf. Process., vol. 34, pp. 339$348,2018$.

[46] W. Tao, X. Su, Y. Chen, and Z. Tian, "Joint formation and fracture characteristics of laser welded CFRP/TC4 joints," J. Manuf. Process., vol. 45, pp. 1-8, 2019.

[47] J. K. Telford, "A brief introduction to design of experiments," Johns Hopkins apl Tech. Dig., vol. 27, no. 3, pp. 224-232, 2007.

[48] M. Moradi and H. Abdollahi, "Statistical Modelling and Optimization of the Laser Percussion Microdrilling of Thin Sheet Stainless Steel.," Lasers Eng. (Old City Publ., vol. 40, 2018. 


\section{Figures}

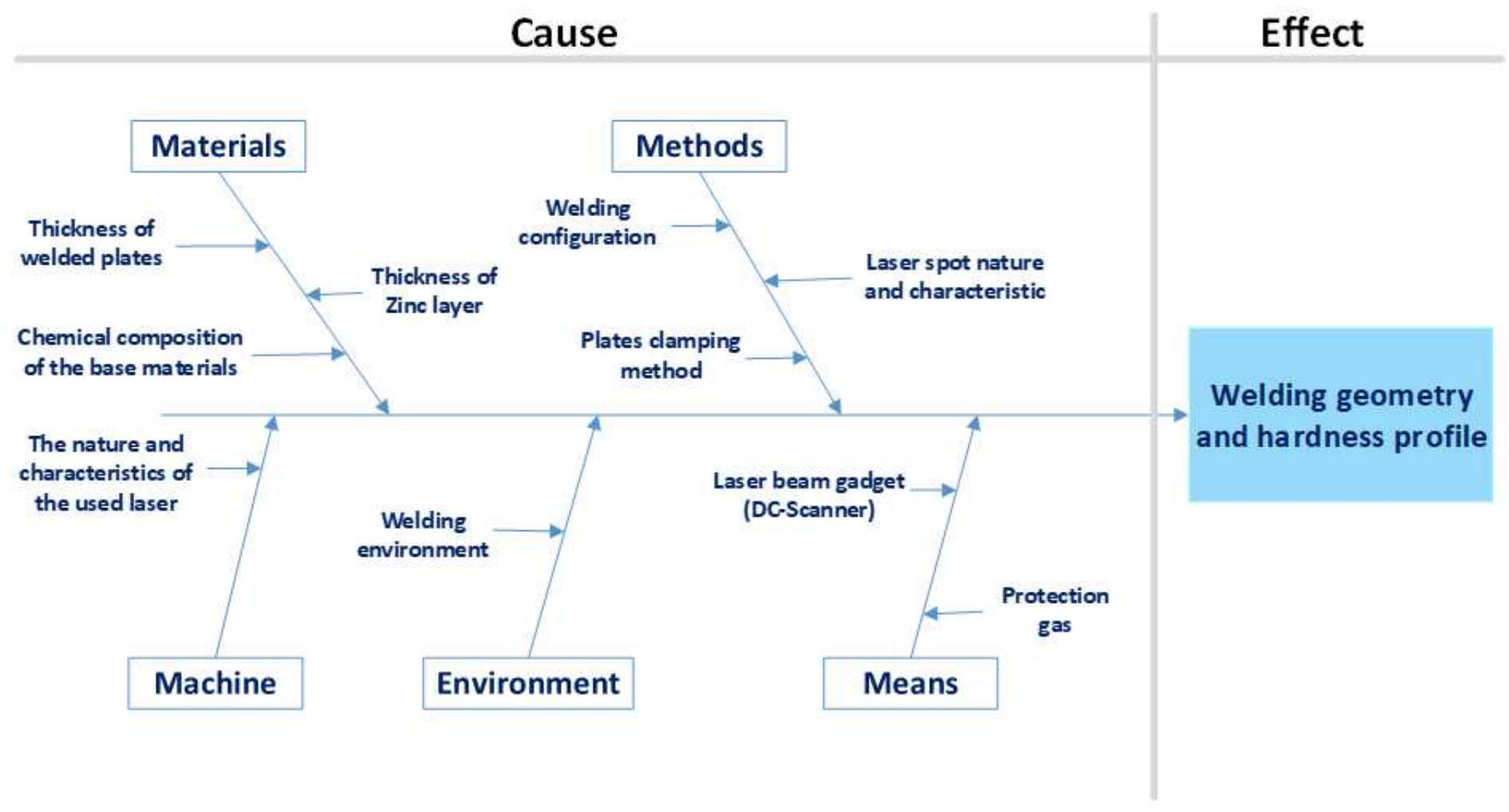

\section{Figure 1}

Ishikawa's diagram analyzing the effect of galvanized steel laser welding on welding geometry and harness profile.

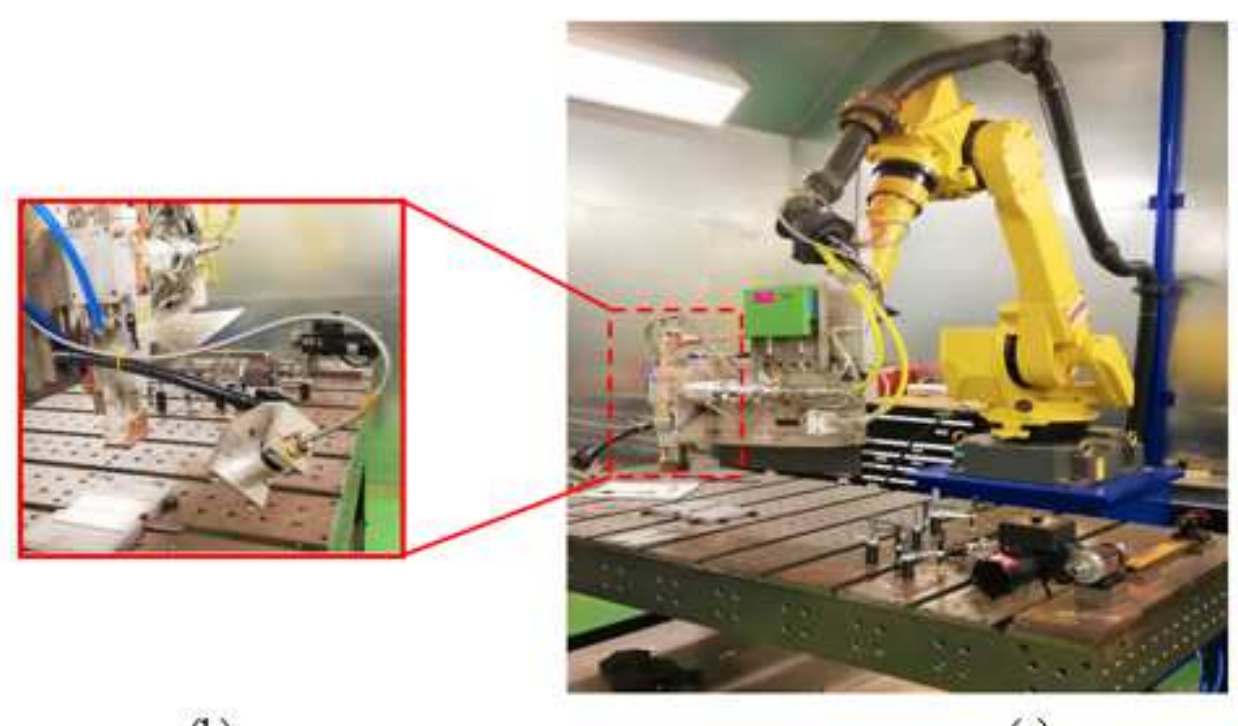

(b)

(a)

\section{Figure 2}

Automatic mechanism of welding machine a) six-axis-robotic system FANUC M-710ic and b) Laser welding cell. 


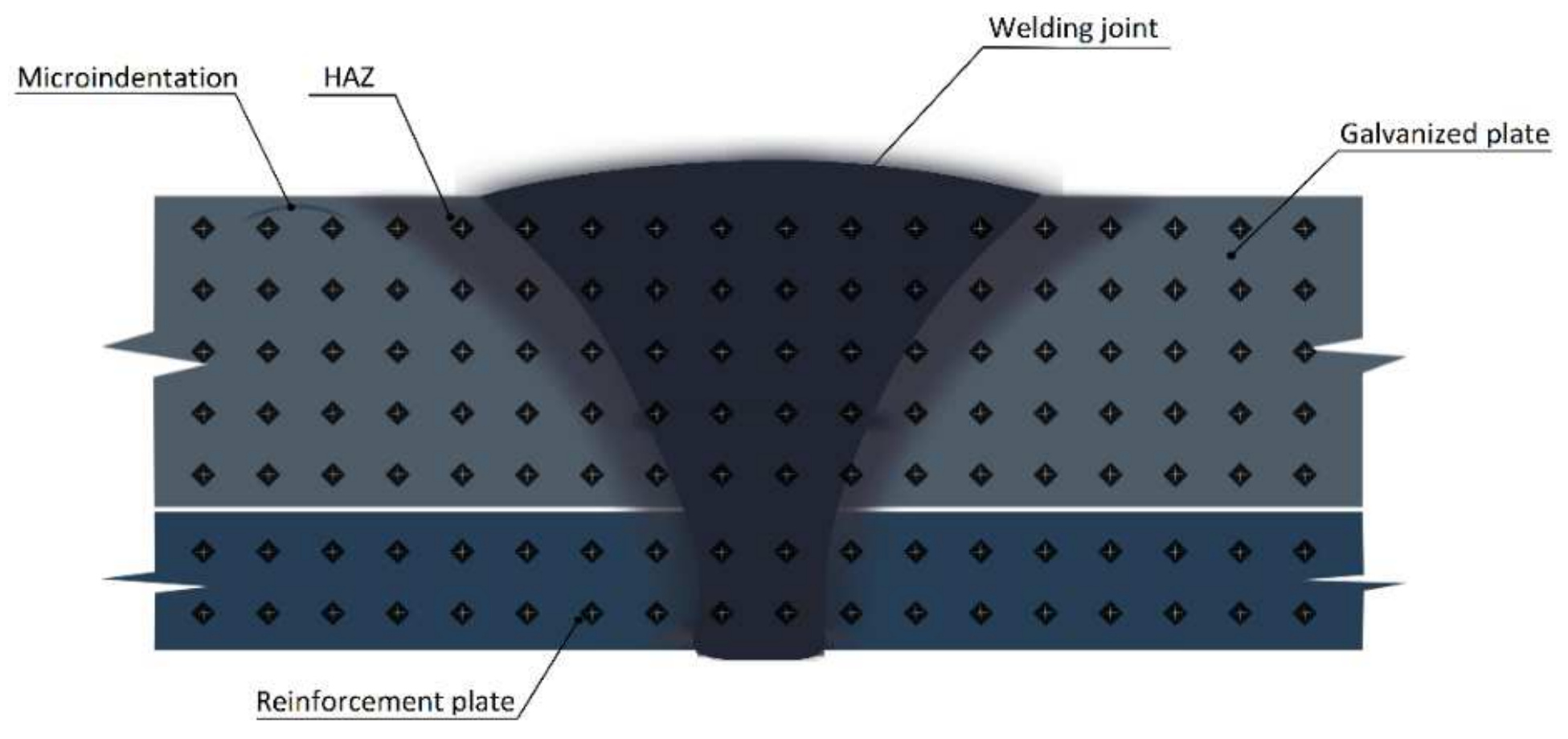

\section{Figure 3}

Schematic representation of micro-indentation matrix pattern over a welding cross-section. [37]

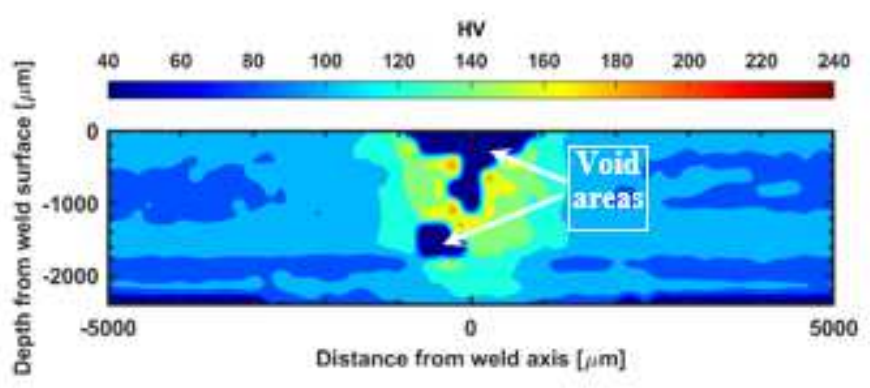

(a)

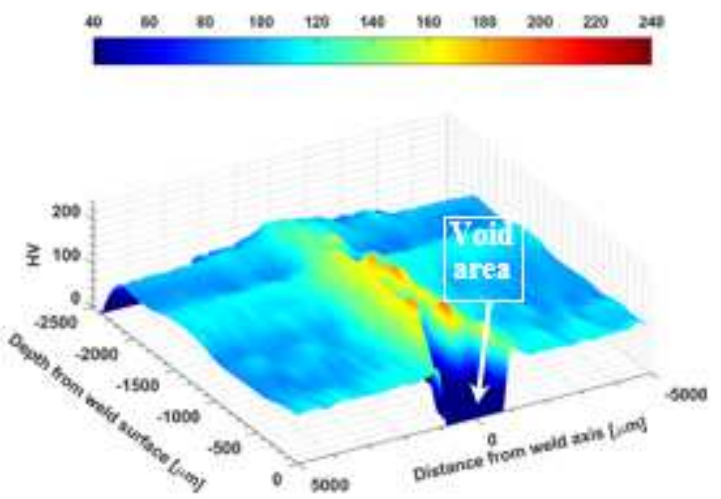

(b)

\section{Figure 4}

Hardness profile of test $1(P=1200 \mathrm{~W}, \mathrm{~V}=13 \mathrm{~mm} / \mathrm{s}, \mathrm{f}=150 \mathrm{~Hz}$ and $\mathrm{g}=0.55 \mathrm{~mm})$ a) contour plot $\mathrm{b})$ 3D surface plot. 


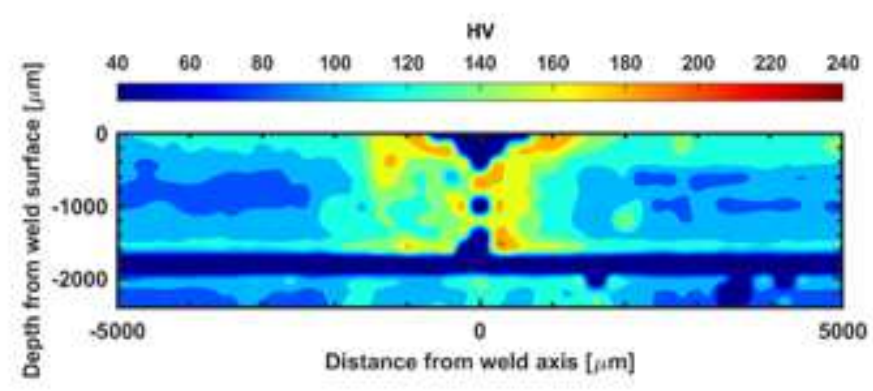

(a)

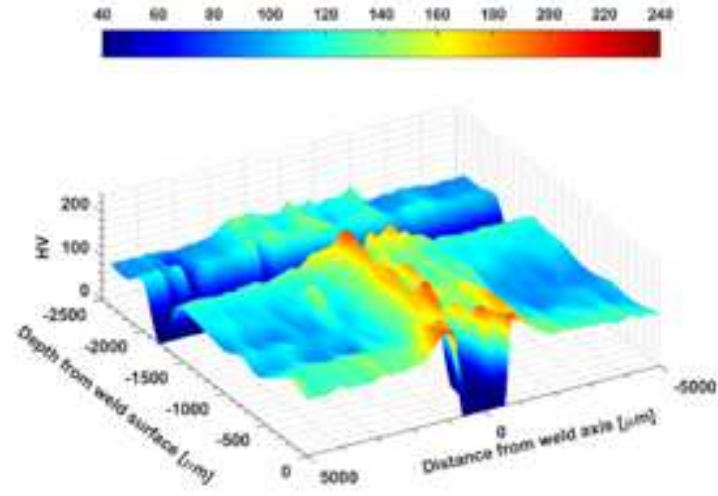

(b)

\section{Figure 5}

Hardness profile of test $2(P=1200 \mathrm{~W}, \mathrm{~V}=10 \mathrm{~mm} / \mathrm{s}, \mathrm{f}=175 \mathrm{~Hz}$ and $\mathrm{g}=0.35 \mathrm{~mm})$ a) contour plot $\mathrm{b}) 3 \mathrm{D}$ surface plot.

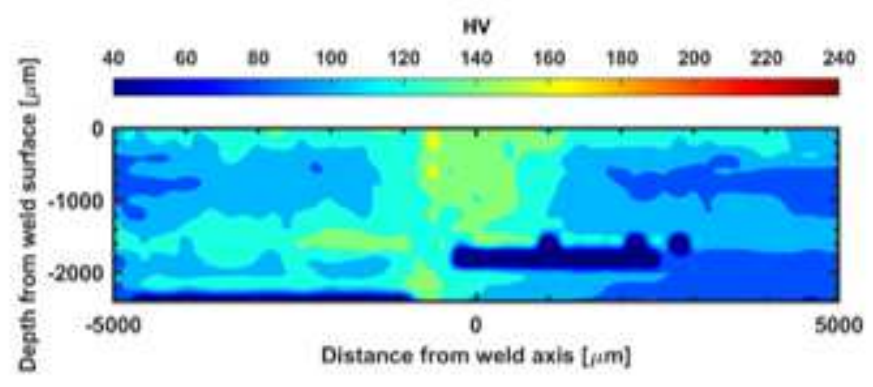

(a)

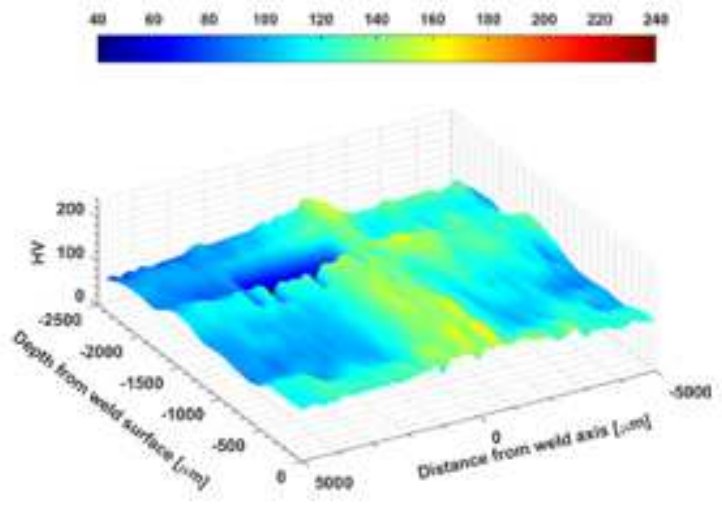

(b)

\section{Figure 6}

Hardness profile of test $3(P=1200 W, V=7 \mathrm{~mm} / \mathrm{s}, f=200 \mathrm{~Hz}$ and, $g=0.15 \mathrm{~mm})$ a) contour plot $b)$ 3D surface plot. 


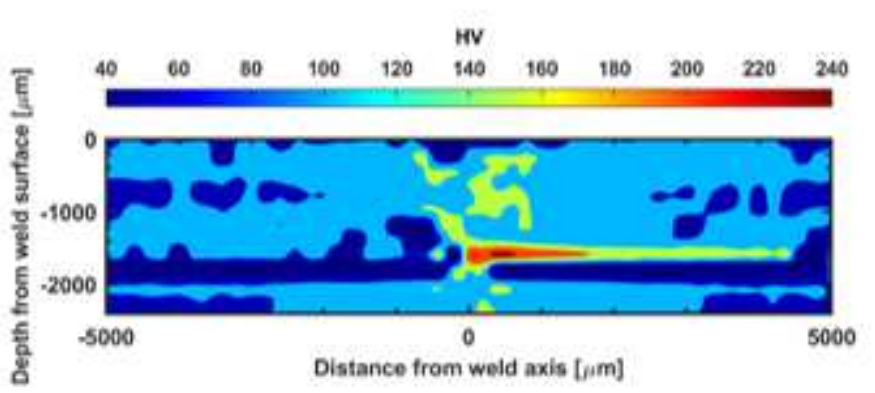

(a)

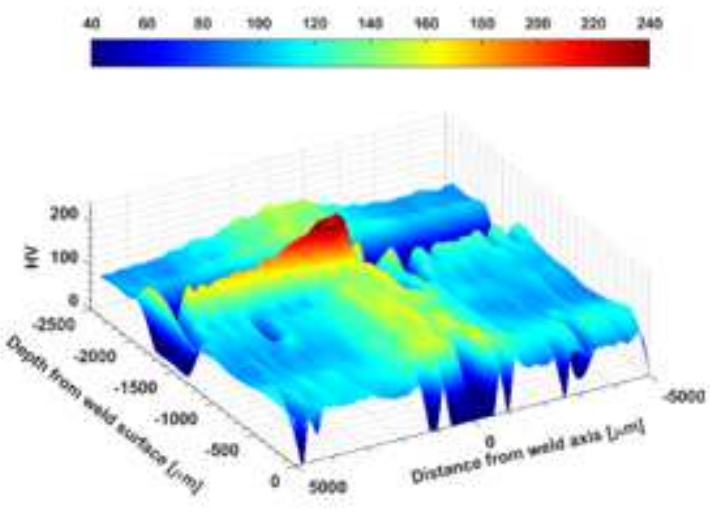

(b)

\section{Figure 7}

Hardness profile of test $4(P=1400 W, V=13 \mathrm{~mm} / \mathrm{s}, \mathrm{f}=175 \mathrm{~Hz}$, and $\mathrm{g}=0.15 \mathrm{~mm})$ a) contour plot b) 3D surface plot.

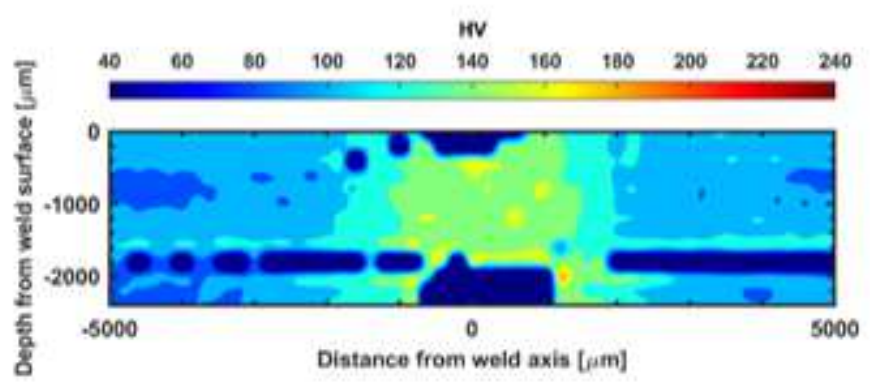

(a)

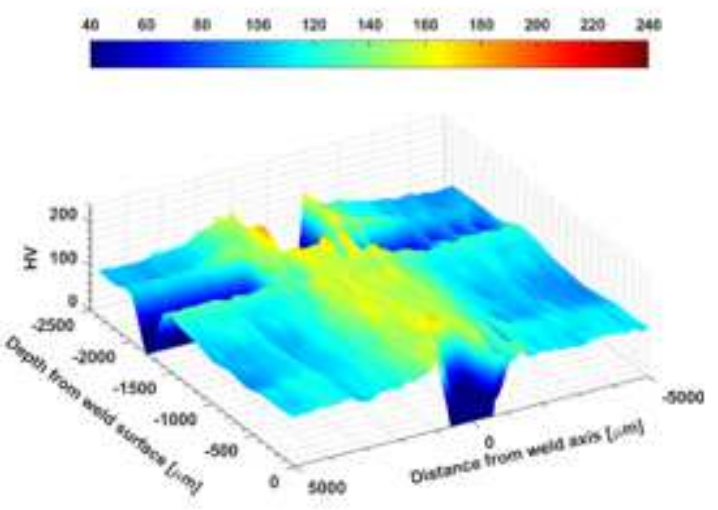

(b)

\section{Figure 8}

Hardness profile of test $5(P=1400 \mathrm{~W}, \mathrm{~V}=10 \mathrm{~mm} / \mathrm{s}, \mathrm{f}=200 \mathrm{~Hz}$, and $\mathrm{g}=0.55 \mathrm{~mm})$ a) contour plot $\mathrm{b}) 3 \mathrm{D}$ surface plot. 


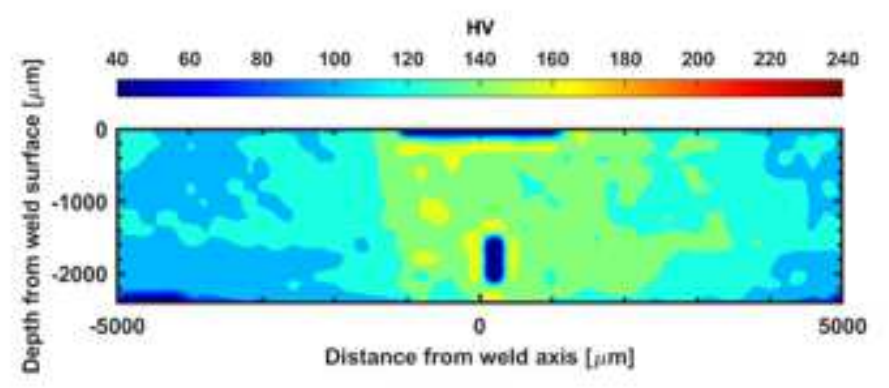

(a)

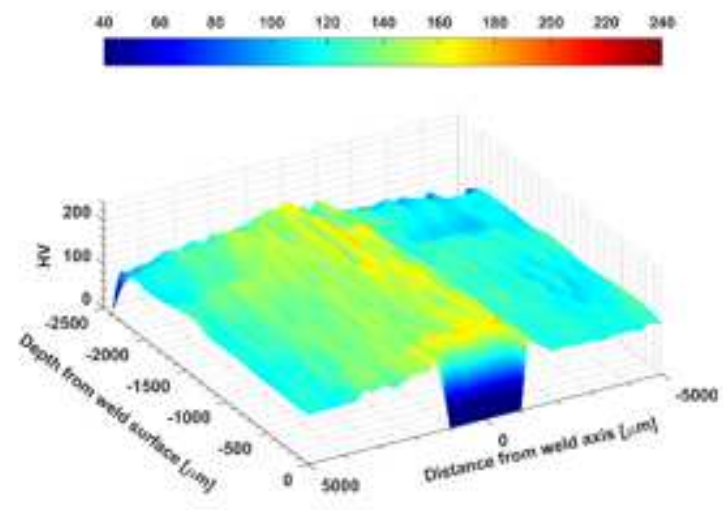

(b)

\section{Figure 9}

Hardness profile of test $6(P=1400 \mathrm{~W}, \mathrm{~V}=7 \mathrm{~mm} / \mathrm{s}, \mathrm{f}=150 \mathrm{~Hz}$, and $\mathrm{g}=0.35 \mathrm{~mm})$ a) contour plot $b)$ 3D surface plot.

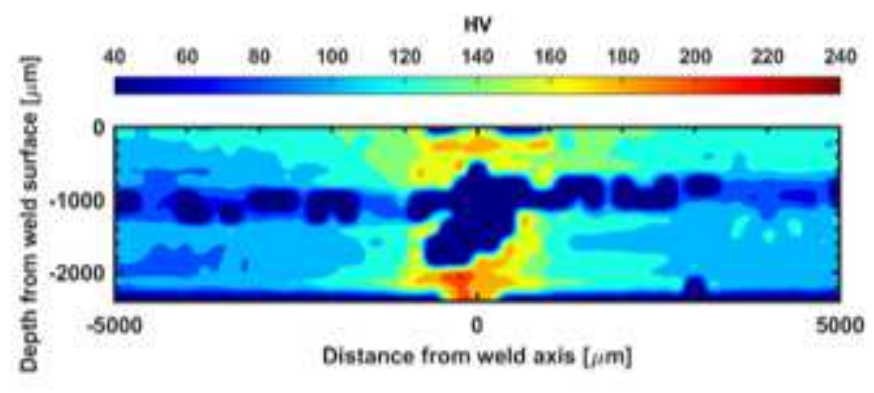

(a)

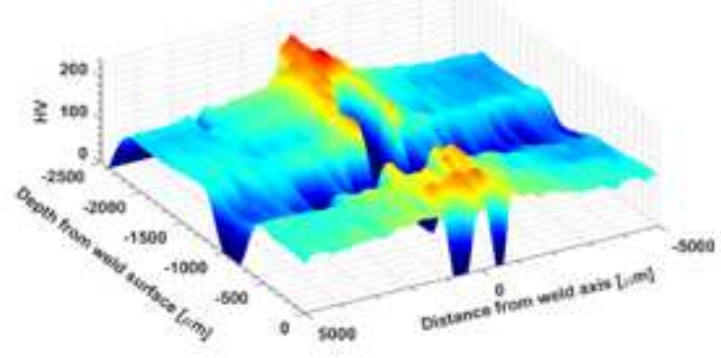

(b)

\section{Figure 10}

Hardness profile of test $7(P=1600 W, V=13 \mathrm{~mm} / \mathrm{s}, f=200 \mathrm{~Hz}$ and, $g=0.35 \mathrm{~mm})$ a) contour plot $b) 3 \mathrm{D}$ surface plot.

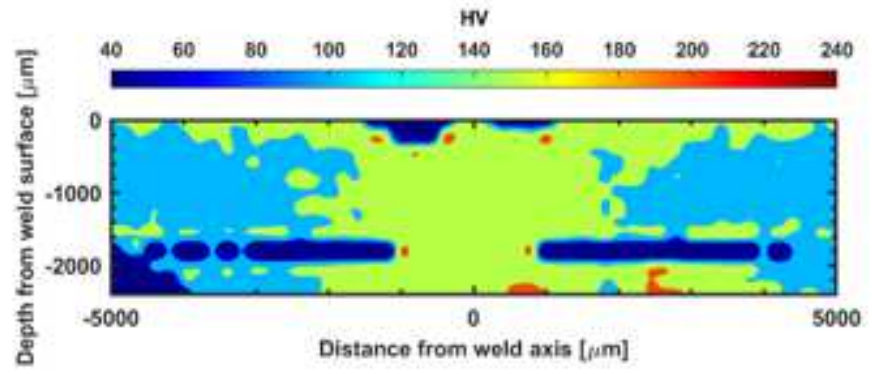

(a)
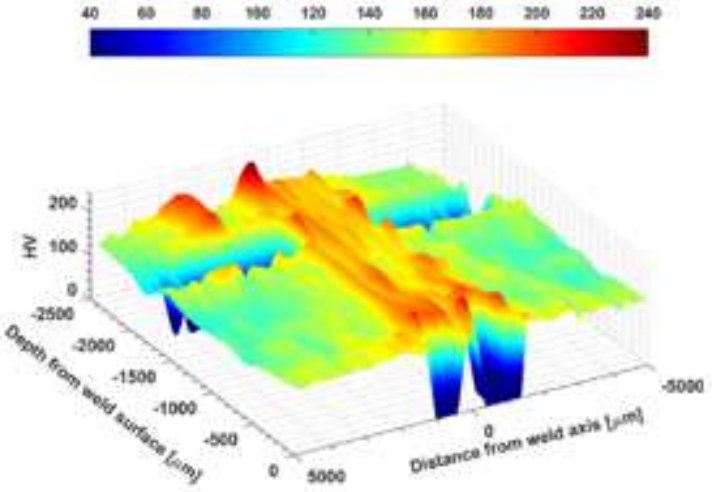

(b) 


\section{Figure 11}

Hardness profile of test $8(P=1600 W, V=10 \mathrm{~mm} / \mathrm{s}, f=150 \mathrm{~Hz}, g=0.15 \mathrm{~mm})$ a) contour plot $b)$ 3D surface plot.

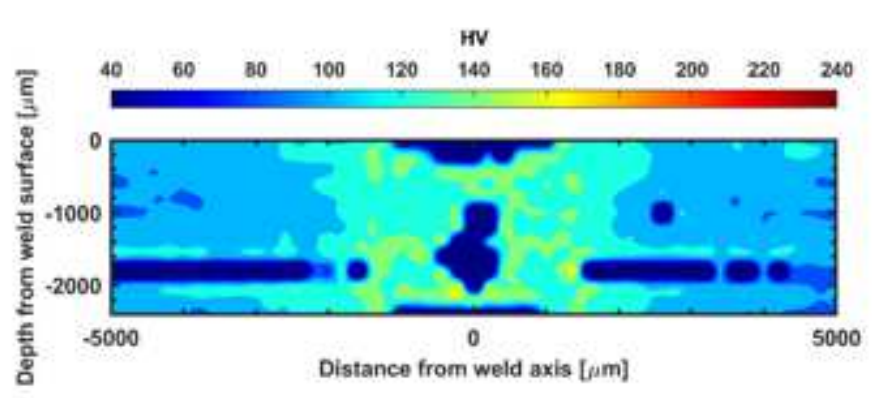

(a)

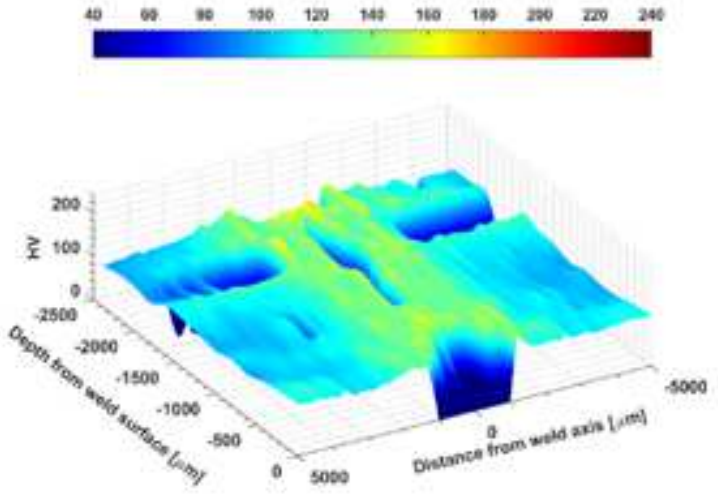

(b)

\section{Figure 12}

Hardness profile of test $9(P=1600 \mathrm{~W}, V=7 \mathrm{~mm} / \mathrm{s}, \mathrm{f}=175 \mathrm{~Hz}$, and $\mathrm{g}=0.55 \mathrm{~mm})$ a) contour plot $b)$ 3D surface plot.
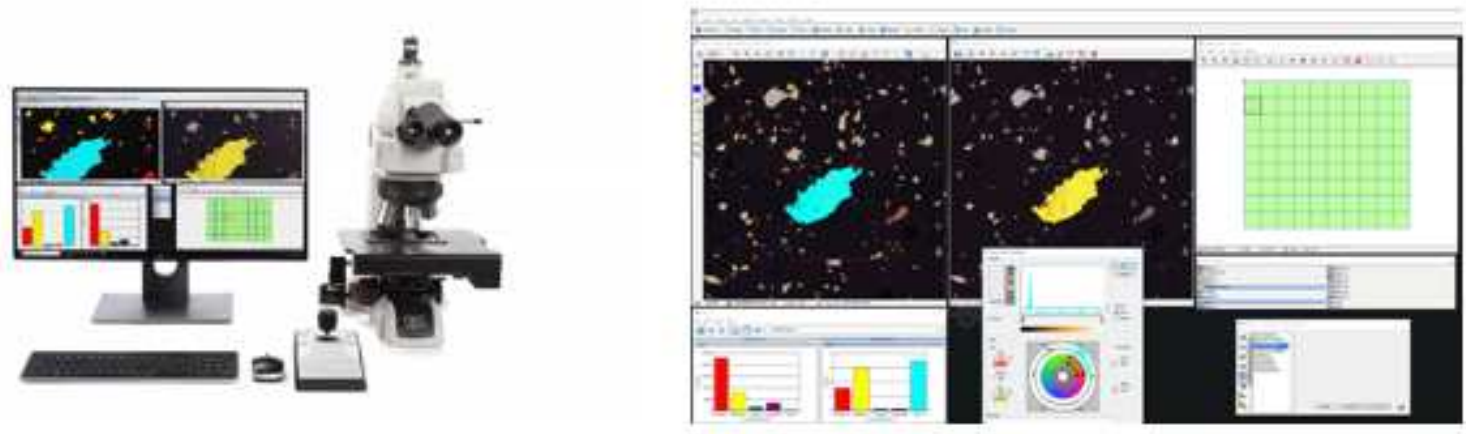

Figure 13

Porosity analysis using a micro-indentation matrix pattern over a welding cross-section [41]. 


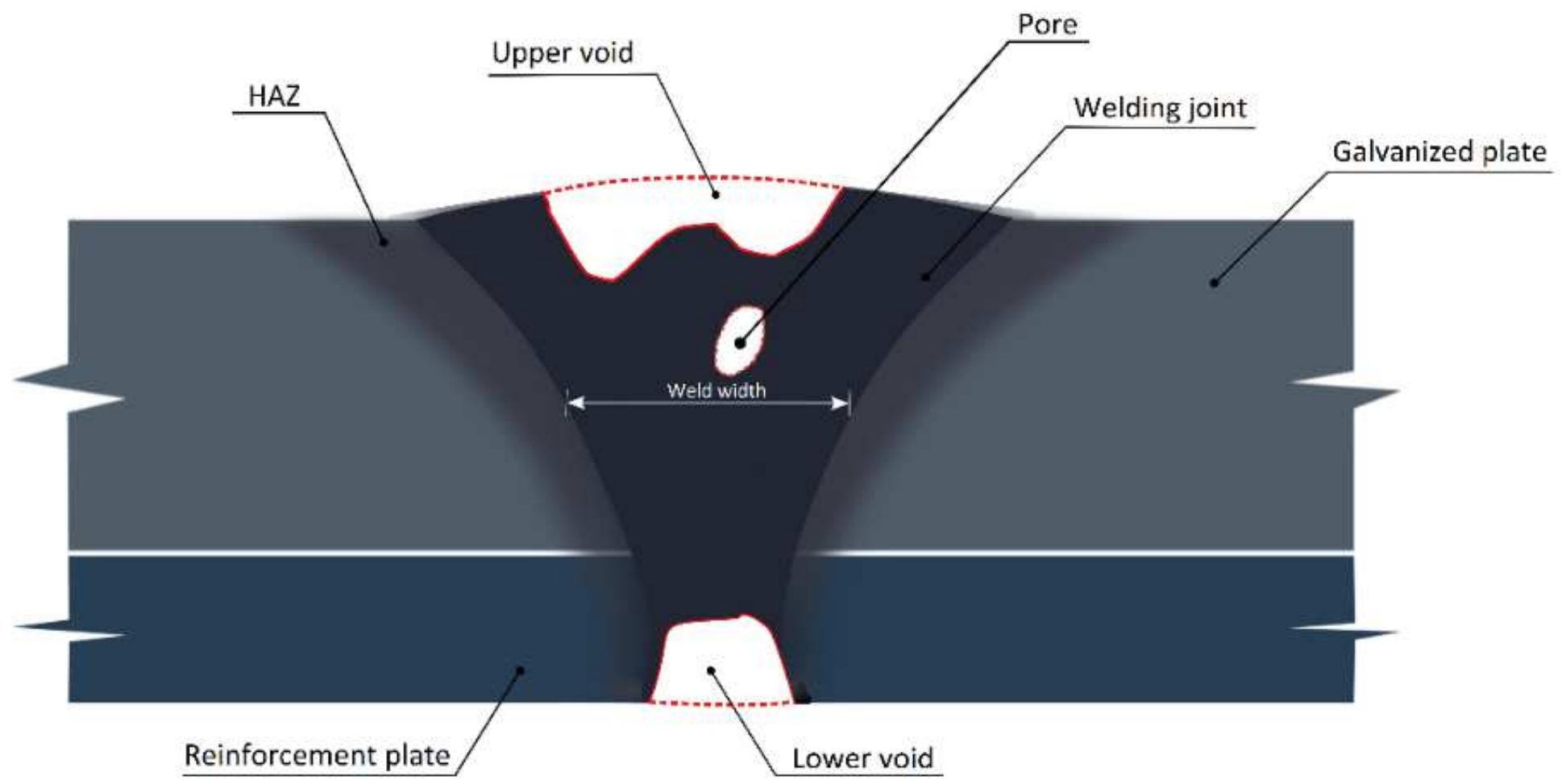

Figure 14

Geometric characteristics of welding and some welding defects schema [37]. 

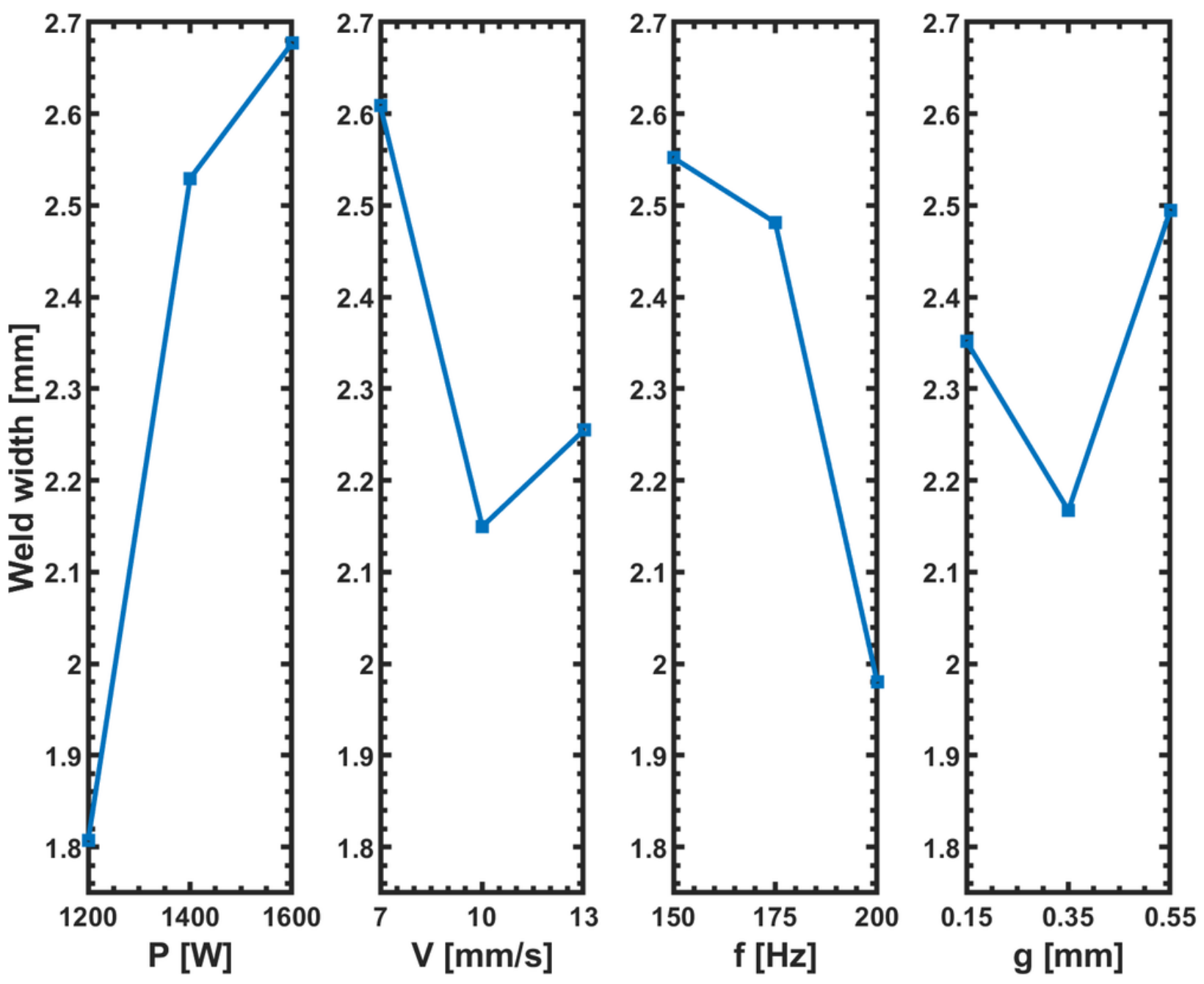

Figure 15

Main effects of parameters on average weld widths. 


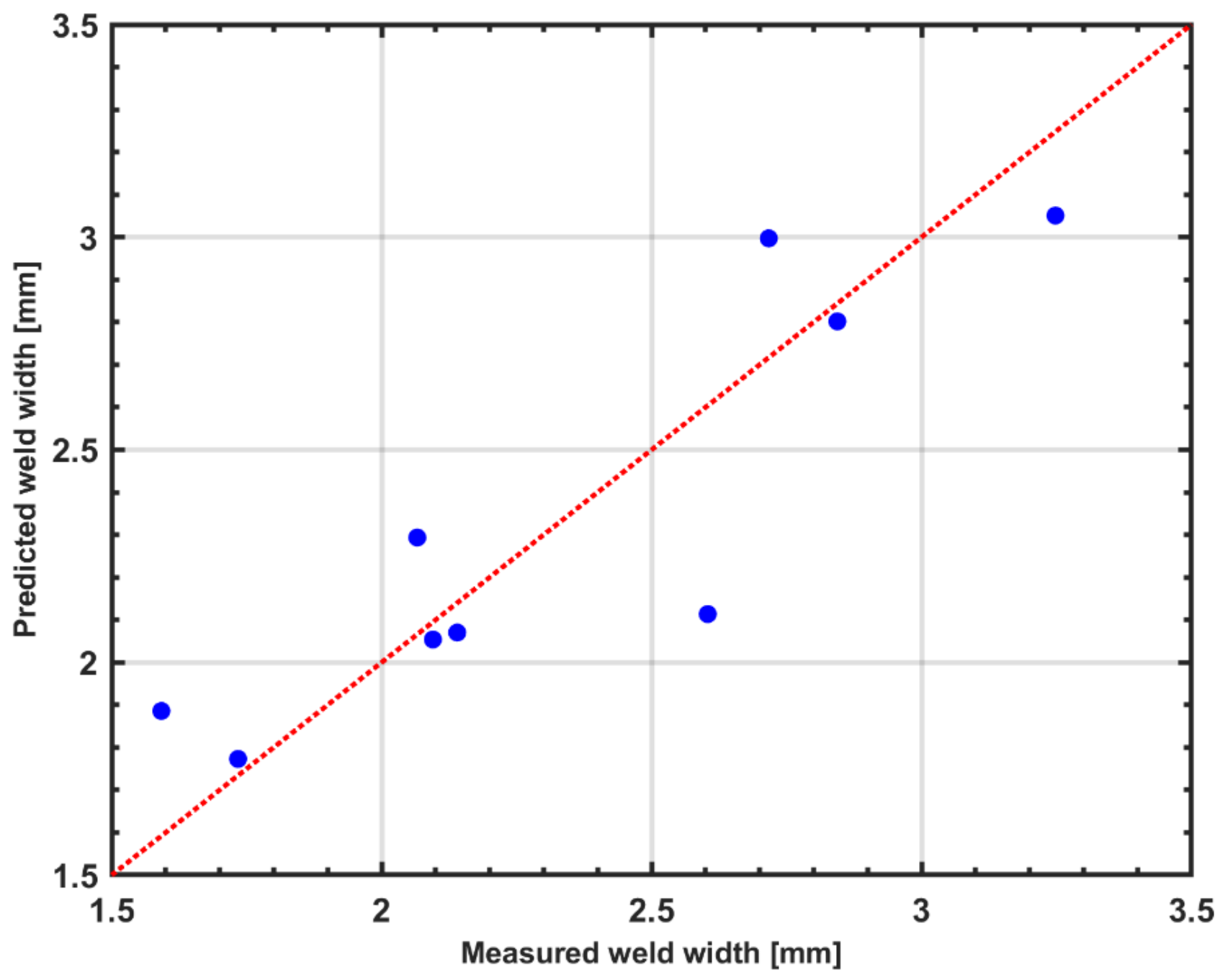

Figure 16

Welding widths measured by experiments versus predicted by regression equations for each experimental test. 

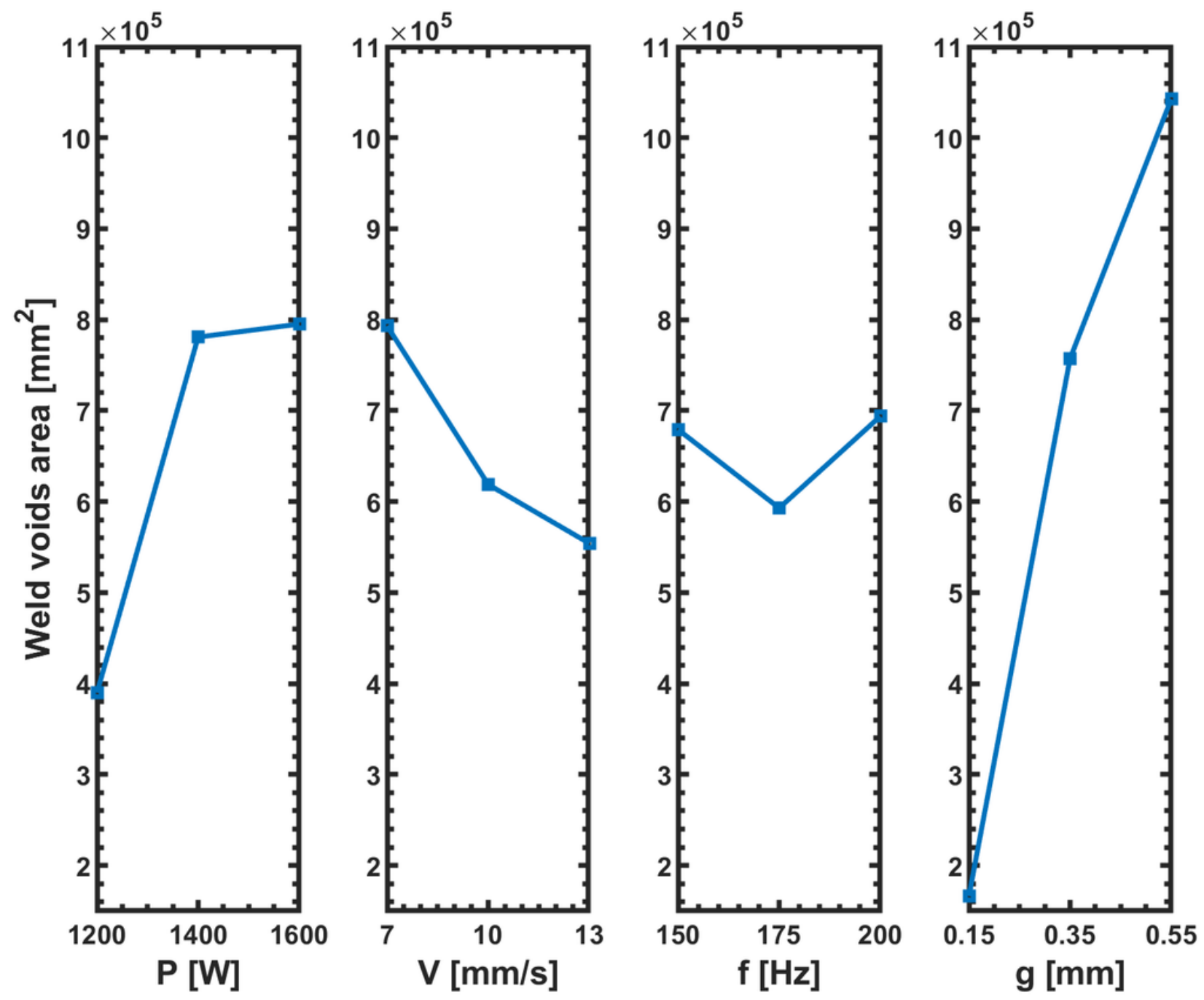

Figure 17

Main effects of parameters on voids area of galvanized laser-welded plates. 


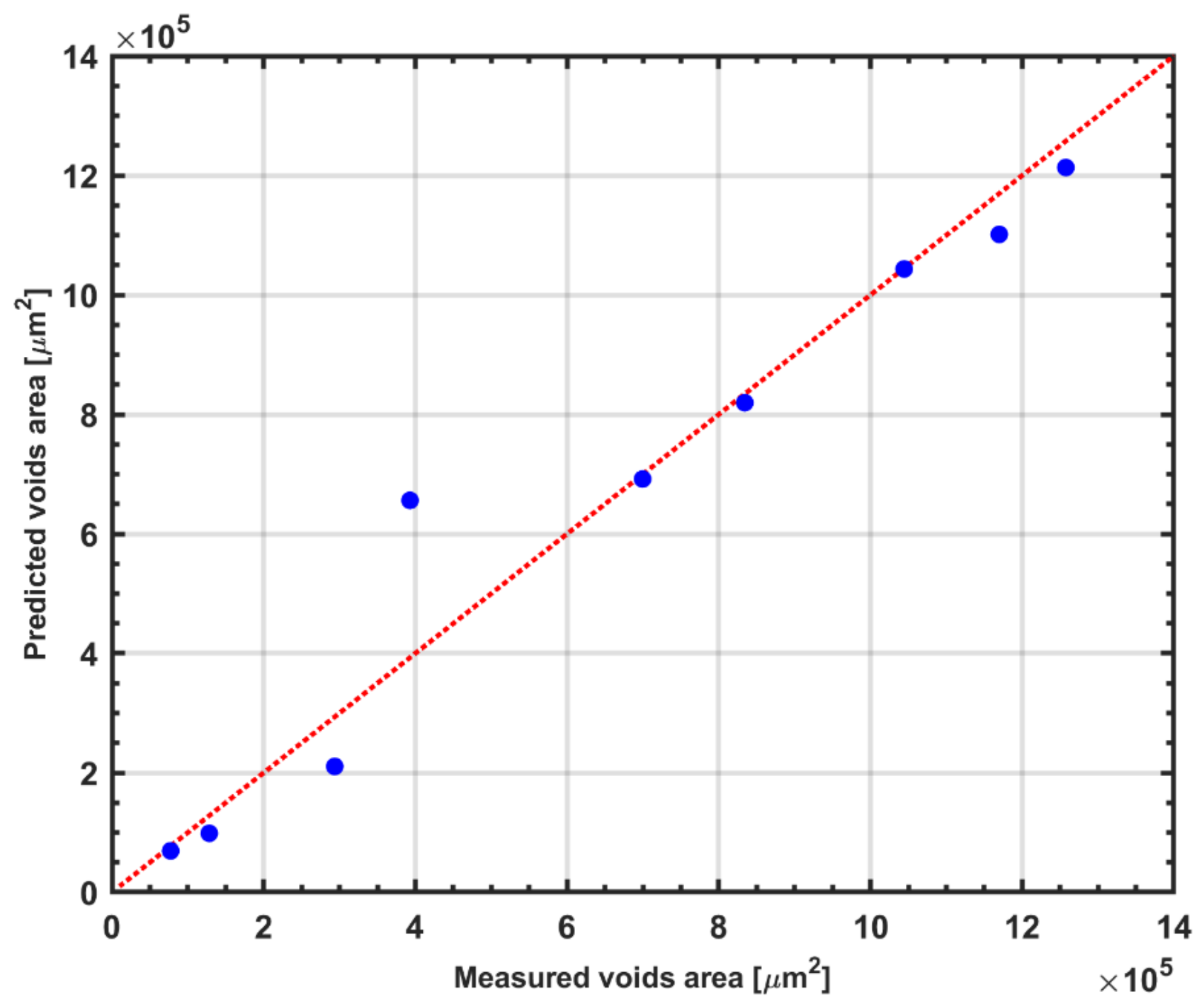

Figure 18

Voids area measured by experiments versus predicted by regression equations for each experimental test. 


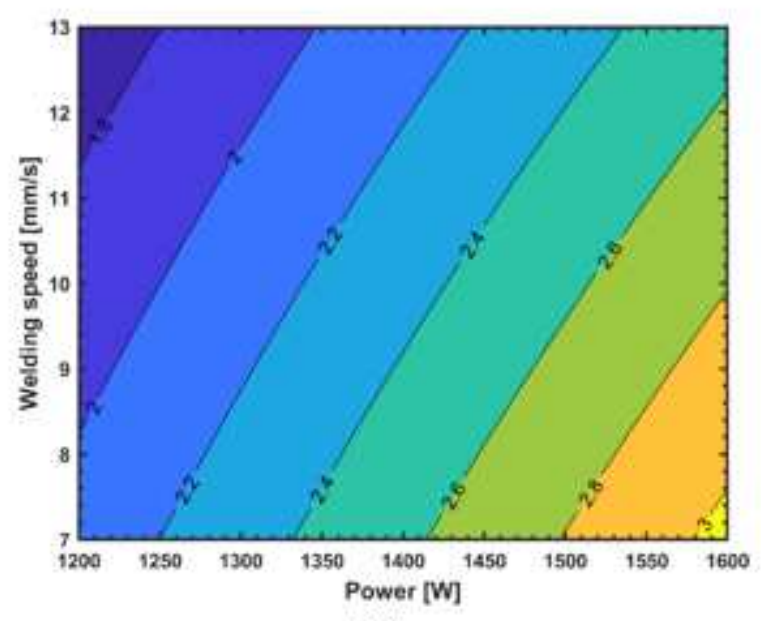

(a)

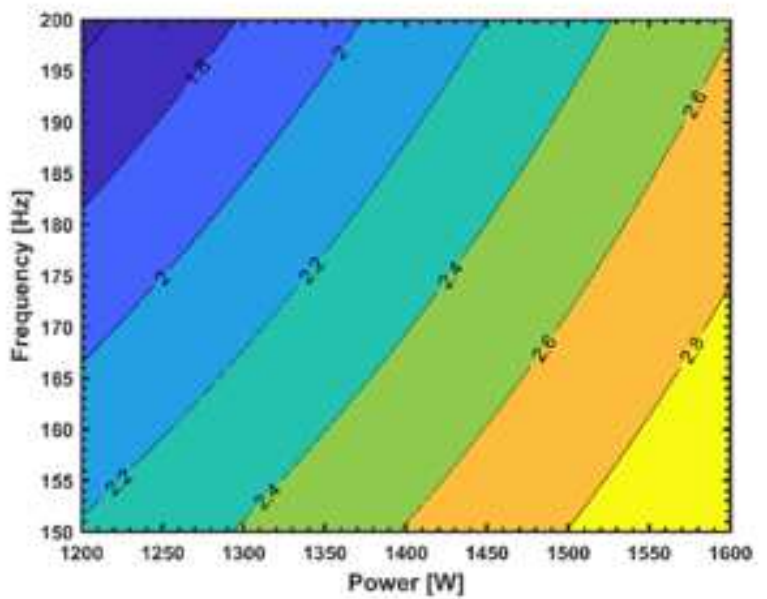

(b)

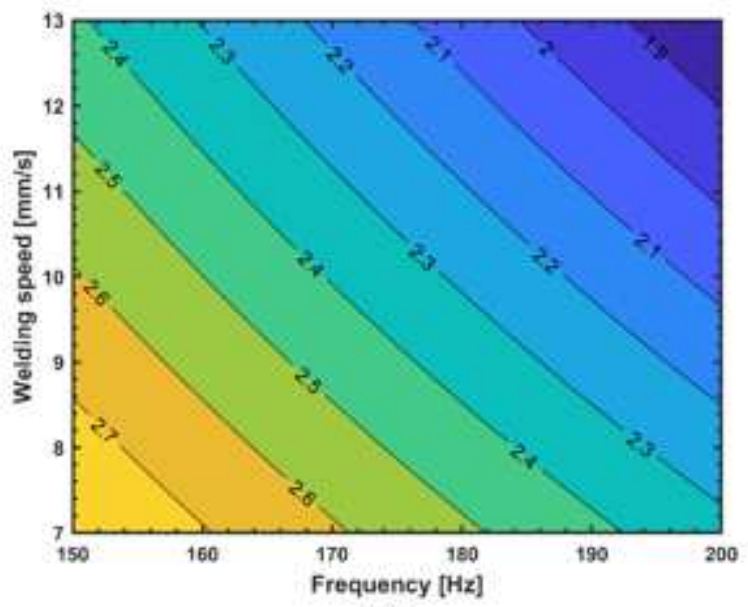

(c)

\section{Figure 19}

The contour plots of process factors interactions on the weld width a) power and welding speed b) power and frequency $\mathrm{c}$ ) welding speed and frequency. 


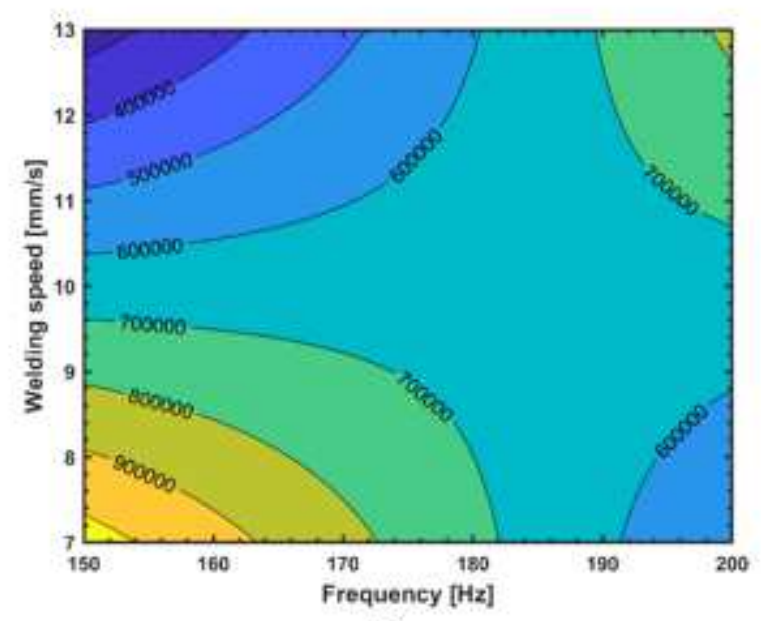

(a)

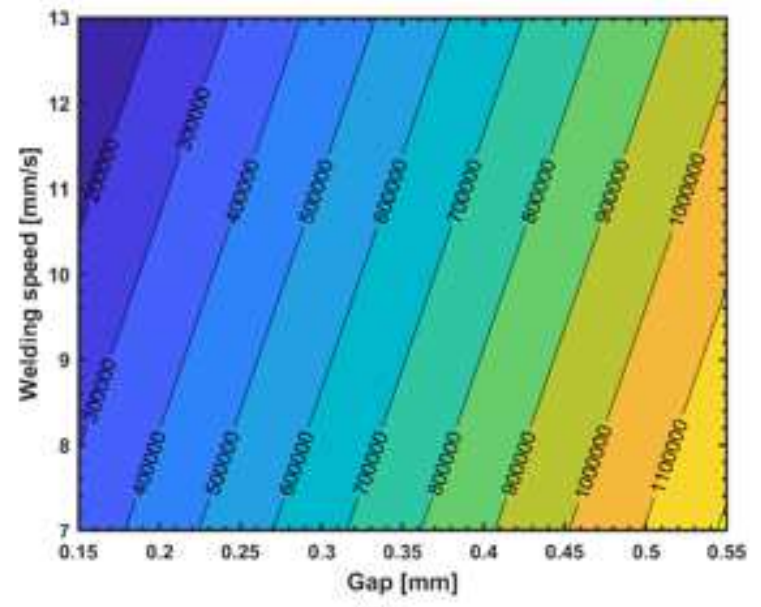

(b)

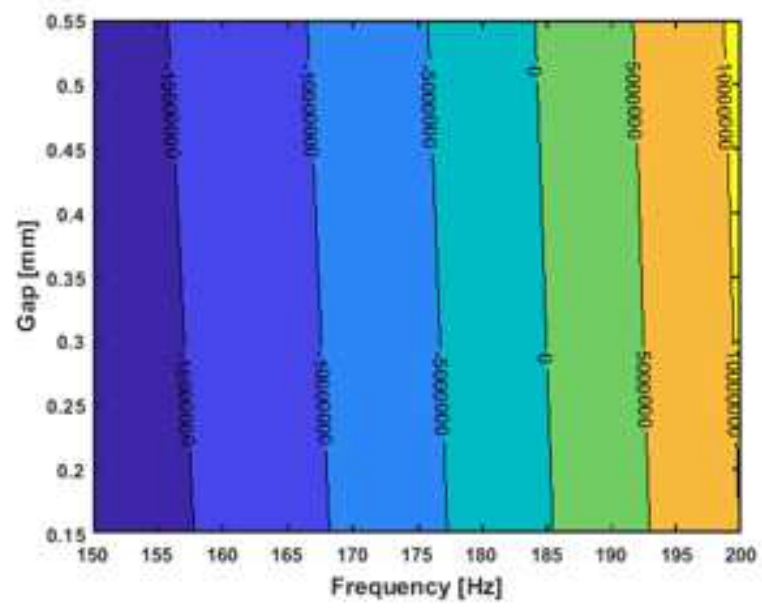

(c)

Figure 20

The contour plots of process factors interaction on the weld voids area a) welding speed and frequency b) welding speed and gap c) frequency and gap 